\title{
CRECIMIENTO ECONÓMICO COLOMBIANO DE 1888 A 2013: UNA NUEVA SERIE DEL PRODUCTO INTERNO BRUTO*
}

Giuseppe B. de Corso

* DOI: https://doi.org/10.18601/01245996.v21n40.10. Este artículo es resultado de la investigación Historia Cuantitativa de Colombia, para la institución Universidad Jorge Tadeo Lozano. Recepción: 02-04-2018, modificación final: 18-08-2018, aceptación: 30-10-2018. Sugerencia de citación: De Corso, G. B. (2019). Crecimiento económico colombiano de 1888 a 2013: una nueva serie del Producto Interno Bruto. Revista de Economía Institucional, 21(40), 259-289.

a Doctor en Ciencias Políticas. Profesor de Análisis de Políticas Públicas, Universidad Jorge Tadeo Lozano, Bogotá, Colombia, [giuseppeb.decorsos@ utadeo.com], [https://orcid.org/0000-0002-4677-5130]. 


\section{Crecimiento económico colombiano de 1888 a 2013: una nueva serie del producto interno bruto}

Resumen. El objetivo de este ensayo es calcular una serie del Producto Interno Bruto de Colombia desde 1888 hasta 2013. Con ese propósito se hizo una estimación propia para el periodo 1888-1929 empleando el método del gasto, la cual se empalmó con los datos oficiales del Dane. El resultado se expresa en dólares de paridad de compra de 2011 para facilitar las comparaciones internacionales.

Palabras clave: PIB, petróleo, café, inversiones, Canasta; JEL: N16.

\section{Colombian economic growth from 1888 to 2013: A new series of gross domestic product}

Abstract. The aim of this paper is to present a historical series of Colombian GDP from 1888 to 2013. For that purpose we have employed an expenditure approach to reconstruct the GDP for the period 1888-1929. We linked it to the official statistics data of the DANE. The result is expressed in 2011 purchasing parity dollars for international comparisons.

Keywords: GDP, oil, coffee, investment, basket; JEL: N16.

\section{Crescimento econômico colombiano de 1888 a 2013: uma nova série do Produto Interno Bruto}

Resumo. O objetivo deste ensaio é calcular uma série do Produto Interno Bruto da Colômbia de 1888 a 2013. Com esse propósito, fez-se uma estimativa própria para o período entre 1888 e 1929 utilizando o método do gasto e que esteve conectada com os dados oficiais do Departamento Administrativo Nacional de Estatística. O resultado é expresso em dólares de paridade do poder de compra de 2011 para facilitar as comparações internacionais.

Palavras-chaves: PIB, petróleo, café, investimentos, cesta básica; JEL: N16. 
H Colombia, como en el resto de América Latina, se ha hecho Cun esfuerzo importante por reconstruir las cuentas nacionales históricas. Los trabajos de Kalmanovitz y López (2009) para el siglo XIX, y la revisión del producto realizada por Greco-Banrep (2004) para el siglo XX, son dos ejemplos destacados.

En este trabajo se propone una serie del Producto Interno Bruto, la más larga hasta ahora, de 1888 a 2013. Para el periodo 1888-1929 se empleó el enfoque del gasto, que es el más apropiado pues incluye la parte del producto no monetizado, es decir, la producción para autoconsumo, que es sustancial en una economía preindustrial. El periodo seleccionado es fundamental, pues permite escrudiñar el desenvolvimiento económico durante la Regeneración y el momento de arranque del crecimiento intensivo. La estimación partió del consumo per cápita, al que se añadieron otros agregados: el gasto fiscal, la formación bruta de capital fijo y el neto de las exportaciones. Esta serie se empalma con los datos oficiales, a partir de 1930, y se elabora una sola serie en pesos corrientes, pesos constantes y dólares de 2011 y 1990. El resultado es una serie histórica del PIB colombiano de 1888 a 2013, es decir, de 125 años.

\section{CONSIDERACIONES SOBRE LAS ESTADÍSTICAS COLOMBIANAS}

Las cuentas nacionales de Colombia han sido elaboradas por dos entidades: el Banco de la República (1950-1969)1 y el Dane (de 1970 en adelante), con aportes importantes de la Cepal (1925-1949) ${ }^{2}$ y han sido revisadas en numerosas ocasiones usando diversas metodologías. Para facilitar el análisis y la comparación con otras series, denominamos Dane-Cepal, o simplemente Dane, a la serie histórica oficial que aparece en el libro Estadísticas históricas de Colombia publicado en $1999^{3}$. Dicho trabajo compila y selecciona las estadísticas oficiales colombianas (PIB, precios, sector externo, etc.) provenientes de las fuentes mencionadas. Es, por tanto, una herramienta fundamental para analizar el PIB colombiano.

Las cifras elaboradas por las diversas entidades muestran algunas inconsistencias. A manera de ejemplo se presentan las gráficas 1 y 2 , que indican el grado de complicación para el investigador. Una

${ }^{1}$ Ver Banco de la República (1997) y Greco-Banrep (1999).

2 Cepal (1957) y Lebret (1958).

${ }^{3}$ Ver DNP (1999). Existe una versión impresa publicada en 1999, y como las cifras del Dane se incluyen en ese libro, aquí se citan simplemente como Dane. 
variable fundamental como la inversión muestra variaciones significativas, y en comercio exterior las diferencias son amplias. Esto señala la importancia de hacer un trabajo minucioso y detallado cuando se examinan las estadísticas económicas colombianas.

Gráfica 1

Estimaciones de la formación bruta de capital fijo, 1925-1997 (Porcentaje del PIB a precios de 1975)

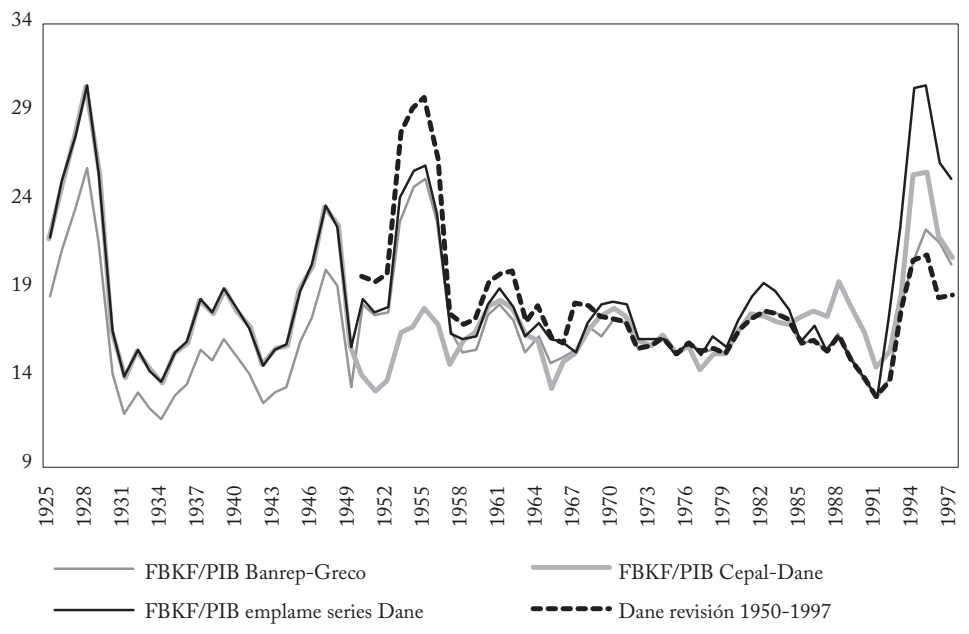

Fuente: Dane, Banrep-Greco, cálculos propios.

\section{Gráfica 2}

Estimaciones de la formación bruta de capital fijo, 1925-1997 (Porcentaje del PIB a precios de 1975, media móvil de 5 años)

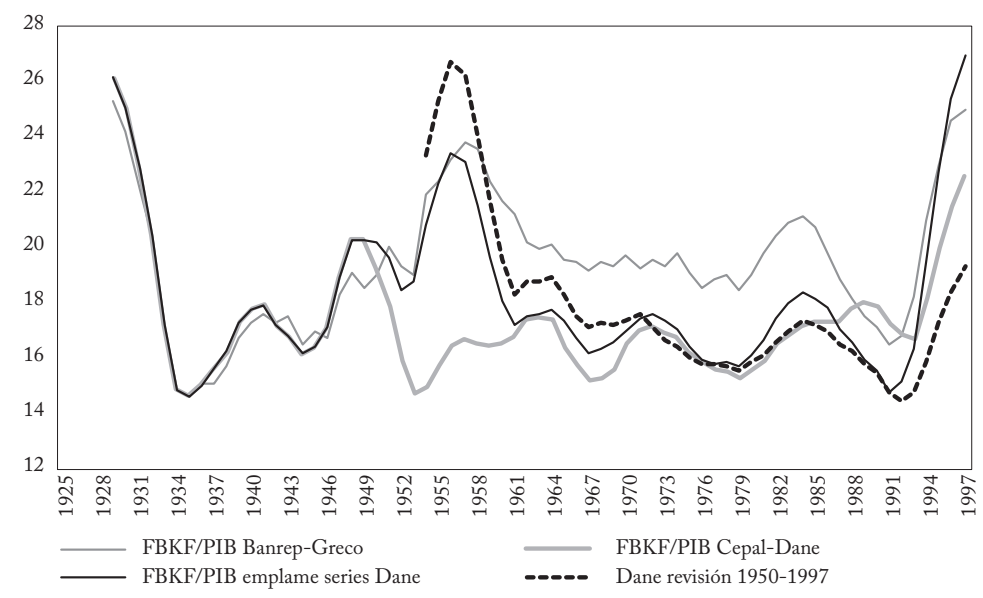

Fuente: Dane, Banrep-Greco, cálculos propios. 
Como se observa, las diferencias en la relación FBKF/PIB, una variable básica para el crecimiento, son marcadas, aunque las tendencias coinciden. Lo mismo ocurre en otro sector clave, el comercio exterior. Según el Dane, las importaciones totales en el periodo 1925-1996 ascendieron a 74.833 .992 millones de pesos y las exportaciones a 70.936.707 millones de pesos, y según el Banco de la República (1997), a 60.403.143 y 55.555.123 millones de pesos, respectivamente. Por tanto, cuando se intenta reconstruir las cuentas nacionales históricas es necesario examinar en detalle las cifras disponibles, pues algunas son contradictorias. No obstante, si se emplea la información del comercio internacional de Banrep para construir una serie alternativa del PIB, que llamamos revisada, las diferencias en el PIB nominal no muestran una brecha importante, como se aprecia en el cuadro 1 (de casi un 13\%). Este cuadro presenta una estimación del PIB usando los datos del Dane ajustados por las cifras del sector externo del Banrep y la compara con las cifras elaboradas por el Dane.

Cuadro 1

PIB corriente Dane y Dane revisado, 1930-1950

\begin{tabular}{|c|c|c|c|c|c|c|c|}
\hline & $\begin{array}{c}\text { PIB } \\
\text { Dane } \\
\text { (Millones) }\end{array}$ & $\%$ & $\begin{array}{l}\text { PIB Dane } \\
\text { revisado } \\
\text { (Millones) }\end{array}$ & $\%$ & $\begin{array}{l}\text { Población } \\
\text { (Miles) }\end{array}$ & $\begin{array}{l}\text { PIB per } \\
\text { cápita } \\
\text { Dane } \\
\text { (Pesos) }\end{array}$ & $\begin{array}{l}\text { PIB per } \\
\text { cápita } \\
\text { Dane } \\
\text { revisado } \\
\text { (Pesos) }\end{array}$ \\
\hline 1930 & 744 & & 675 & & 8.317 & 89,46 & 81,15 \\
\hline 1931 & 590 & $-20,70$ & 556 & $-17,55$ & 8.483 & 69,55 & 65,60 \\
\hline 1932 & 529 & $-10,34$ & 486 & $-12,69$ & 8.653 & 61,13 & 56,15 \\
\hline 1933 & 575 & 8,70 & 525 & 8,01 & 8.826 & 65,15 & 59,46 \\
\hline 1934 & 849 & 47,65 & 822 & 56,71 & 9.002 & 94,31 & 91,35 \\
\hline 1935 & 901 & 6,12 & 816 & $-0,76$ & 9.183 & 98,12 & 88,87 \\
\hline 1936 & 1.003 & 11,32 & 860 & 5,40 & 9.366 & 107,09 & 91,84 \\
\hline 1937 & 1.049 & 4,59 & 927 & 7,71 & 9.554 & 109,80 & 96,98 \\
\hline 1938 & 1.256 & 19,73 & 1.045 & 12,79 & 9.745 & 128,89 & 107,23 \\
\hline 1939 & 1.379 & 9,79 & 1.217 & 16,42 & 9.959 & 138,47 & 122,16 \\
\hline 1940 & 1.430 & 3,70 & 1.173 & $-3,61$ & 10.179 & 140,49 & 115,21 \\
\hline 1941 & 1.397 & $-2,31$ & 1.236 & 5,41 & 10.402 & 134,30 & 118,84 \\
\hline 1942 & 1.532 & 9,66 & 1.315 & 6,37 & 10.631 & 144,11 & 123,69 \\
\hline 1943 & 1.818 & 18,67 & 1.404 & 6,77 & 10.865 & 167,33 & 129,22 \\
\hline 1944 & 2.233 & 22,83 & 1.844 & 31,31 & 11.104 & 201,10 & 166,03 \\
\hline 1945 & 2.799 & 25,35 & 2.235 & 21,23 & 11.349 & 246,63 & 196,93 \\
\hline 1946 & 3.332 & 19,04 & 2.956 & 32,28 & 11.598 & 287,29 & 254,90 \\
\hline 1947 & 4.015 & 20,50 & 3.391 & 14,70 & 11.854 & 338,70 & 286,07 \\
\hline 1948 & 4.704 & 17,16 & 3.974 & 17,19 & 12.115 & 388,28 & 328,02 \\
\hline 1949 & 5.509 & 17,11 & 5.212 & 31,15 & 12.381 & 444,96 & 420,96 \\
\hline 1950 & 7.860 & 42,68 & 7.652 & 46,81 & 12.568 & 625,40 & 608,82 \\
\hline Media & 2.167 & 13,56 & 1.920 & 14,28 & 10.292 & 210,54 & 186,55 \\
\hline
\end{tabular}

Fuente: Dane, Banrep-Greco, cálculos propios. 
Convirtiendo las cifras anteriores a precios de 1975 se obtiene la gráfica 3, que muestra el PIB per cápita y el coeficiente entre el ingreso por habitante de la serie del Dane y la revisada. Con las cifras del sector externo que estima el Banrep, el ingreso per cápita promedio de la serie revisada es de 6.766 pesos y en la del Dane es de 7.702 pesos. La volatilidad de la serie del cuadro 1, calculada con base en la desviación estándar, es mayor en la serie revisada, 8,54 puntos, mientras que en la del Dane es de solo 2,93. Si bien, la tasa de crecimiento promedio del PIB revisado es mayor, 4,93\%, que la del Dane, 4,03\%, el PIB promedio es inferior, 70.642,33 millones de pesos y $80.504,08$ millones de pesos, respectivamente.

\section{Gráfica 3}

PIB per cápita Dane y Dane con sector externo Banrep, 1930-1950 (Pesos de 1975)

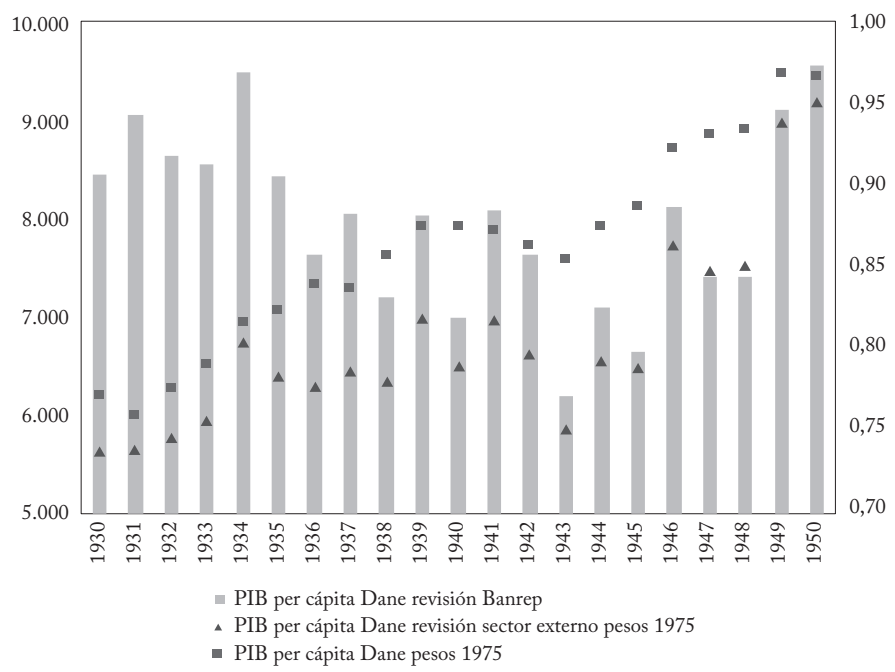

La columna (eje derecho) corresponde al coeficiente entre el PIB per cápita Dane y la serie revisada. Fuente: Dane, Banrep-Greco y cuadro 1.

El ejercicio con la serie del periodo 1930-1993 (se usó como límite 1993, pues en 1994 cambió la base) se presenta en la gráfica 4. La volatilidad es de 5,1 en la estimación revisada y de 2,26 en la del Dane, y, como en la de 1930-1950, el ingreso per cápita promedio a precios constantes es algo menor en la serie revisada (12.202 pesos, mientras que en la del Dane es de 12.672) y la tasa de crecimiento del PIB es ligeramente mayor en la serie revisada, el 4,70\%, mientras que en la oficial es del 4,51\%. 
Así mismo, se muestra un diagrama de dispersión (gráfica 5) que establece la relación entre el PIB del Dane y el volumen de comercio exterior del Banrep, que se correlacionan positivamente. E1 resultado es una asociación muy alta entre ambas variables, lo que lleva a inferir que las cuentas nacionales han sido elaboradas con un énfasis excesivo en el comportamiento del sector externo, aunque el grado de apertura comercial ha sido históricamente bajo.

Gráfica 4

PIB y coeficiente serie Dane y serie revisada, 1930-1993

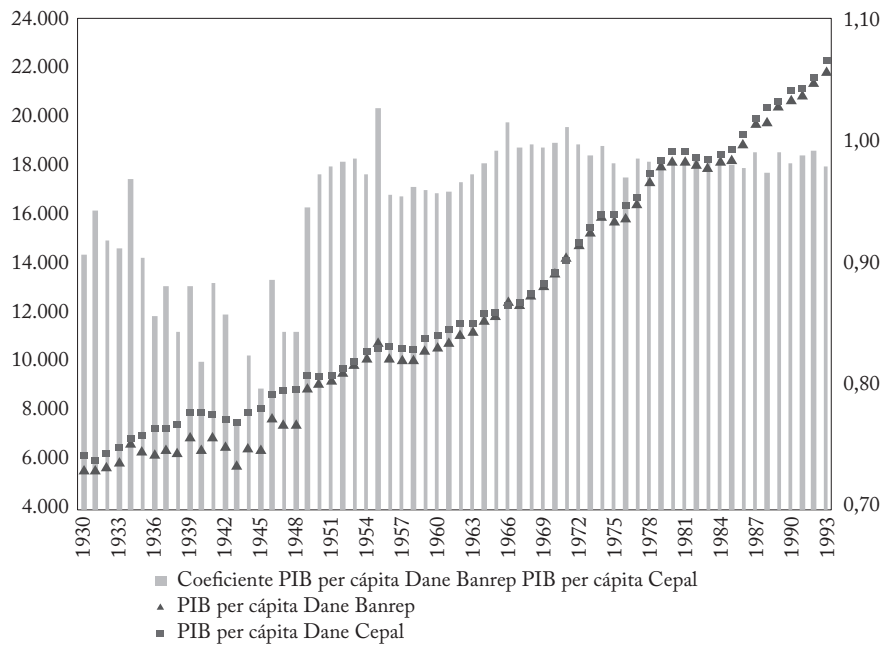

Fuente: Dane, Banrep-Greco, cálculos propios.

Este breve ejercicio alternativo -que excluye las inversiones de la medición- supondría que la tasa de crecimiento del PIB, utilizando las cifras de comercio exterior del Banrep, podría ser algo mayor que la del Dane, mientras que el PIB y el ingreso per cápita en valores absolutos serían menores, un 5\% inferiores a los oficiales, lo cual es un margen de error aceptable. Por ejemplo, el producto promedio del periodo $1930-1993$ es de 288.422 millones de pesos con la serie oficial y de 276.855 millones con la serie revisada. Por último, y este es el punto más interesante que queremos resaltar, la volatilidad de la economía colombiana se duplicaría. Por cierto, esa volatilidad se acentúa en el periodo 1930-1948, es decir, con la Gran Depresión y con la Segunda Guerra Mundial; el ciclo se cierra con el Bogotazo. 


\section{Gráfica 5}

PIB y comercio exterior, 1930-1993

(Millones de pesos)

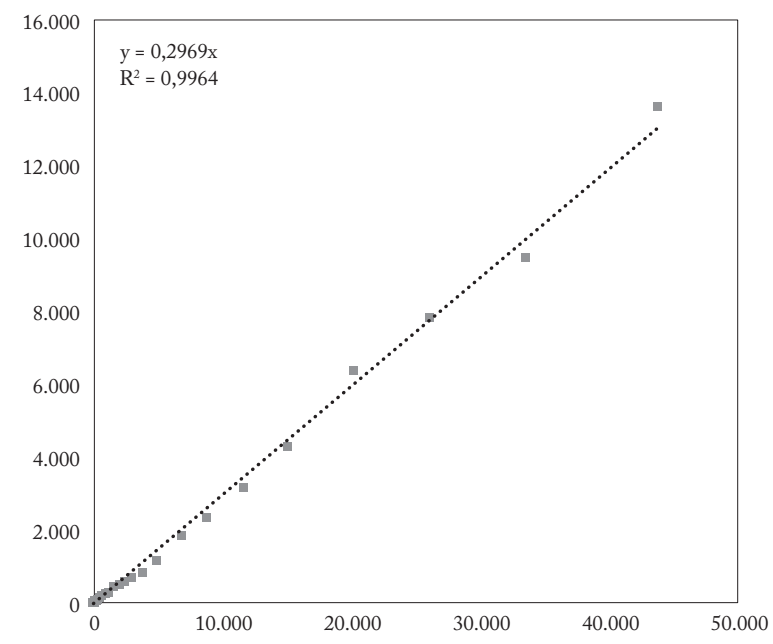

Fuente: Dane, Banrep-Greco.

Cabe añadir que la base de datos Moxlad (consultada en 2016) muestra dos series de precios corrientes durante el periodo 1936-2000, que para facilitar su manejo se denominan escenario A (1lamado vigente en Moxlad) y B. La diferencia entre los PIB nominales es cercana al 20\%, el producto corriente promedio del periodo $1936-2000$ es de 15.751.212 millones de pesos en el escenario A y de 12.466.892 millones en el escenario B. No obstante las múltiples imprecisiones y correcciones de las cifras oficiales y la falta de explicaciones suficientemente razonadas y detalladas, ese trabajo se sirve de las estadísticas oficiales del Dane.

Para cerrar esta sección, cabe mencionar algunas diferencias entre la serie que aquí se propone y la de Greco. La nuestra, como se expone en la sección siguiente, se construye a partir del consumo de la población, que en una economía preindustrial, y esa era la fisonomía de la economía colombiana de la época, puede representar un 90\% del PIB. Esta es una condición de las economías agrícolas premodernas, ampliamente examinada y aceptada en la literatura sobre la reconstrucción de cuentas nacionales. De modo que el método aquí empleado es directo y tiene bases comprobadas y sólidas. Por otra parte, se hace una lectura histórica de acontecimientos como la Guerra de los Mil Días, la pérdida del Estado Soberano de Panamá, los efectos de la Primera Guerra Mundial y la crisis de 1920-1921 
(depresión deflacionaria que duró unos 18 meses). Greco, en cambio, obtiene el producto (1905-1923) empleando un modelo monetarista, donde $\mathrm{Q}=\mathrm{MV} / \mathrm{P}$, o sea PIB = (Cantidad de dinero $\mathrm{x}$ Velocidad de circulación $) /$ Nivel de precios, en un país donde no existía un banco central de emisión y había una gran escasez monetaria, atemperada por los superávits de la balanza comercial, y por ende una alta velocidad de circulación monetaria. Además, la apertura al comercio internacional en relación con el PIB era muy baja, y la serie de población no se examinó exhaustivamente. Esas son algunas debilidades de los supuestos que utiliza la estimación de Greco, aunque es un ejercicio interesante para reconstruir el crecimiento económico de Colombia.

\section{MÉTODO PARA ESTIMAR LA SERIE}

Se empleó el enfoque del gasto, que parte de reconstruir el consumo de la población mediante la ecuación $\mathrm{PIB}=\mathrm{C}+\mathrm{G}+\mathrm{I}+(\mathrm{X}-\mathrm{M})(\mathrm{el}$ cuadro A2 del anexo presenta el PIB desagregado en porcentajes para 1888-1929). El consumo es el principal componente del producto en una economía preindustrial ${ }^{4}$, entre un $80 \%$ y un $90 \%$ del PIB. E1 consumo privado colombiano se obtiene multiplicando las cantidades (canasta expresada en $\mathrm{kg}$ ) por los precios, y dicho valor por la población. Este procedimiento supone la existencia de series largas de comercio exterior, del fisco, de población y, especialmente, de precios de alimentos de la dieta tradicional y algunos productos manufacturados, como textiles.

La reconstrucción para el caso colombiano se complica por la penuria $y^{1}$ a incongruencia de las series de precios y los vacíos en los datos de comercio internacional. Fue necesario, entonces, hacer varias operaciones contables especiales: 1) construir una canasta nacional de consumo para el periodo 1888-1929; 2) recabar precios de algunas regiones y ponderarlos para inferir unos precios nacionales; 3 ) despejar la inflación en papel moneda y llevar los precios a pesos oro, desde finales del siglo XIX hasta comienzos del siglo XX; 4) construir un deflactor para expresar la serie en precios constantes; 5) seleccionar las cifras de gasto fiscal y comercio internacional, considerando los patrones históricos que se pueden deducir de un análisis del fisco y del sector externo en el largo plazo y, por último, 6) construir la serie de población.

En sociedades premodernas los productos alimenticios de consumo masivo eran cereales, dependiendo de la región y del entorno

${ }^{4}$ Sobre la estructura de las economías premodernas es fundamental el texto de Malanima (2009). 
agrológico, complementados con porciones de carne, tubérculos y bebidas como guarapo o cerveza. La dieta era relativamente simple y compuesta por pocos rubros. Es conveniente tener una idea del consumo nacional de subsistencia, que cubra la cantidad de productos consumidos, expresados en calorías y kilogramos por habitante. En Colombia no se dispone de una posible canasta de consumo nacional de subsistencia para el periodo $1888-1929^{5}$. Para superar este escollo, y a pesar de las hondas diferencias entre regiones, hay un conjunto de productos alimenticios estratégicos en la dieta, que se consumen en mayor o menor medida, en diversas presentaciones, en todas las regiones del país. A partir de dichos productos se elaboró una canasta de subsistencia nacional para calcular el consumo de los hogares en ese periodo: papa, maíz, panela, arroz, plátano, carne y yuca.

Así, sin más preámbulos, se estimó el consumo promedio posible. En total escogimos dieciocho productos comestibles: azúcar, arroz, cacao, café, carne, harina de trigo, como proxies de pan, maíz, manteca, miel, panela, papa, sal, plátano, yuca, chocolate, huevos y sal. La canasta pesa en promedio $384,6 \mathrm{~kg}$ y tiene un valor kilocalórico de unas 2.300 calorías diarias. Los productos alimenticios estratégicos corresponden al 81,9\% del consumo. Es decir, el grueso de la canasta corresponde a los productos de mayor consumo en el mercado interno, y su participación en la canasta se correlacionó con estadísticas de producción agrícola de diversas fuentes ${ }^{6}$, considerando las posibles pérdidas en el almacenamiento y la distribución.

También se incluyeron algunas manufacturas y fuentes de energía: textiles, escobas, carbón vegetal y leña. Dicha canasta representa el consumo básico por habitante del país, incluye personas de todas las edades, pero la ingesta de un infante es un 60-70\% de la de un adulto. Es una canasta sencilla, pero suficientemente representativa del consumo medio per cápita probable de la población en alimentos, manufacturas y energía. La ponderación final que se obtuvo, y que se empleó como referencia para construir el deflactor, fue: $74,46 \%$ en alimentos, $20,10 \%$ en manufacturas/gastos varios y 5,42\% en energía. Como es imposible que todos los habitantes consumieran exactamente las mismas cantidades, lo que reflejaría una sociedad de iguales con un coeficiente de Gini igual a 0, multiplicamos la canasta por 0,5

${ }^{5}$ Poveda (2005) hace útiles apreciaciones sobre la alimentación de los colombianos. Para información de productos, ver Pardo (1972), y de precios, Urrutia y Arrubla (1970), Urrutia (2007) y López (2011). Sobre la elaboración de canastas de subsistencia, ver Scheidel (2009).

${ }^{6}$ Ver los importantes trabajos sobre la agricultura de Kalmanovitz (1999) y Kalmanovitz y López (2012). 
para tomar en cuenta las diferencias de ingresos. Este coeficiente de $0,5^{7}$ refleja la relación en la distribución del ingreso entre los diversos estratos de población común a las sociedades agrarias premodernas. Donde, en general, el 10\% de la población controlaba un $40 \%$ del ingreso nacional.

Se encontraron otras dificultades que fue necesario resolver. Las series de comercio exterior son imprecisas, aunque Ocampo (1984) aclaró el desempeño global del sector externo colombiano entre 1830 y 1910. Así mismo, las publicaciones de Greco-Banrep y Estadisticas históricas de Colombia registran el comercio exterior con algunas lagunas, que se llenaron con base en las exportaciones cafeteras mencionadas en Graham (1912). Para el gasto fiscal, seleccionamos los datos propuestos por Kalmanovitz para el siglo XIX ${ }^{8}$, y por Junguito y Rincón (2004) para el siglo XX. La serie de Kalmanovitz, que excluye el pago de deuda, es muy completa, no presenta vacíos, se expresa en pesos plata y refleja las pautas de la relación gasto público/PIB observadas en las primeras décadas del siglo XX.

Las inversiones se dedujeron retropolando los datos de Greco hasta 1898 y ajustándolos con datos de importaciones tomados del trabajo de Ocampo. Desde 1888 hasta 1898 se usó el coeficiente venezolano combinado o corregido por los datos de importaciones de bienes de capital del estudio de Ocampo y las cifras de exportaciones estadounidenses de bienes de capital e intermedios a Colombia, que representaban cerca del 80\% de los bienes de capital para la industria textil (DCL, 1907). Cabe subrayar que los datos de inversión del periodo 1888-1929 se elaboraron con cifras de importaciones de bienes de capital, como maquinaria textil (Montenegro, 2002), y de inversiones extranjeras en áreas de alta concentración de capital foráneo, como ferrocarriles y expansión de la producción de café. Se examinó, igualmente, la propuesta de Greco sobre la evolución de la FBKF discutida en el disco compacto mencionado en la nota 8.

\section{POBLACIÓN}

La estimación de la población es esencial para calcular el PIB per cápita. A este respecto se observan importantes diferencias en las estadísticas demográficas. Por ejemplo, alrededor del censo de 1905 se proponen diez estimaciones distintas; Poveda (2013, p. 40) cita cifras

7 Lo Cascio y Malanima (2009).

${ }^{8}$ Los datos se obtuvieron del CD estadístico del trabajo de Meisel y Ramírez (2010). De acuerdo con los estudios de Kalmanovitz, el peso oro (0,965 dólares) tenía un 3,5\% menos valor que el peso fuerte de plata. 
de 3,8 a 4,9 millones, y no incluye las etnias indígenas. Ante esas dificultades se decidió usar las cifras del trabajo de Yáñez, Rivero et al. (2012), quienes hacen un cuidadoso análisis de los censos oficiales de toda América Latina y de diversas series (Moxlad, Mitchell, Maddison y Cepal). Entre 1888 y 2013 la población creció a un promedio anual del 2,05\%. La población colombiana se multiplicó unas 14 veces, de 3,9 millones a 49 millones de habitantes, que viven en el territorio nacional. Es muy difícil estimar el número de colombianos y sus descendientes que residen en el exterior. Guarnizo (2006, p. 84) indica que 5.243.208 colombianos de nacimiento vivían fuera del país en 2003, con base en registros del Ministerio de Relaciones Exteriores. E1 Dane da una cifra de 3,4 millones, de acuerdo con el Censo de 2005. Mientras que las propias comunidades elevan el número a 9 millones. En suma, los colombianos residentes en el exterior hoy oscilan en un rango de mínimo 6 millones a máximo 9 millones, según si las fuentes son oficiales, oficiosas o independientes. Suponiendo para cada colombiano un descendiente de segunda y tercera generación, la población colombiana en el extranjero superaría los 12 millones de personas.

El caso de la migración en el corredor colombo-venezolano amerita algunos comentarios, por su impacto demográfico y su importancia como proporción de la población de ambos países. Para ello se estima el orden de magnitud de la comunidad de origen colombiano en Venezuela (tres generaciones ${ }^{9}$ ). El año base es 1965 , cuando ya era considerable la llegada de inmigrantes a Venezuela, y para la estimación se usaron las defunciones y la tasa de mortalidad (2,3 por mil) del grupo etario colombiano de 15 a 65 años (80\% de los migrantes registrados en el censo de 1961), aplicando la tasa de crecimiento censal a toda la serie. Con este método, los nacidos en Colombia y residentes en Venezuela pasan de 461.250 (indocumentados y regulares) en 1965 a 3.363 .740 en 2015 , es decir, de un 5\% a un 11\% de la población de Venezuela. Cabe señalar que esta estimación es inferior a las de fuentes oficiosas e independientes, que hablan de 4 a 4,5 millones. Además, conviene subrayar que los censos venezolanos son técnicamente incompletos al empadronar a los extranjeros. La

9 La primera generación corresponde a los nacidos en Colombia. La segunda generación se define de manera amplia: personas con uno o ambos padres colombianos, es decir, con derecho a la ciudadanía colombiana conforme al artículo 96 de la Constitución de 1991. La tercera corresponde a personas con abuelos colombianos. E1 censo venezolano de 2011 registró 721.000 nacidos en Colombia, de ellos 302.000 naturalizados y 1.099.999 hijos de madre colombiana.

Revista de Economía Institucional, vol. 2 i, N. ${ }^{\circ}$ 4O, enero-junio/20i9, Pp. 259 -289 ISSN OI 24-5996/E-ISSN 2346-2450 
pregunta de origen nacional es de respuesta voluntaria y no se exige documento de identidad al censado. Esto redunda positivamente en el empadronamiento del total de población, pues las personas en condición irregular no se sienten intimidadas.

De esos 3,3 millones colombianos, unos 600 mil son naturalizados venezolanos (441.569 entre 2004 y 2010), 1,1 millones tienen residencia, 1 millón son transeúntes (visas temporales o familiares) y 600 mil sin documentos. E1 81\% pertenece al grupo de 15 a 64 años de edad, y la edad media es de 44 años. Las continuas legalizaciones, muchos naturalizados directamente, han permitido integrar de manera progresiva a la población colombiana. Entre 1960 y 2010 se legalizaron 1.784.728 colombianos (incluye la Matrícula de Extranjería de 1981 y el Decreto 2.823 de 2004), cifra que no incluye el cambio de visas de turismo a trabajo ${ }^{10}$. El 29,5\% de ellos se legalizó entre 1960 y 1983, el 15,2\% de 1984 a 2003 y el 55,92\% de 2004 a 2010. E1 número de legalizados es cuatro veces superior al promedio de inmigrantes colombianos registrados en los censos de 1961 a 2011. $\mathrm{E} 1$ origen regional de los inmigrantes es: el 58\% de la Costa Caribe, el 11,3\% de Norte de Santander, el 5,5\% de Santander, el 5,4\% del Valle, el 4,5\% de Antioquia, el 4,4\% de Bogotá y el resto de otros departamentos. Cabe señalar que el $29,8 \%$ de la población colombiana en Venezuela proviene de dos departamentos, Atlántico y Bolívar. Según el censo venezolano de 2011, el 31,52\% de los inmigrantes colombianos llegados a Venezuela desde 1950 arribó entre 2001 y 2011 , lo que coincide, grosso modo, con el segundo auge petrolero y la implementación de programas sociales llamados misiones.

La segunda generación es fácil de estimar, a través de los registros civiles y las estadísticas vitales ${ }^{11}$. En Venezuela se aplica el ius soli puro desde 1999, es decir, incluso los hijos de extranjeros indocumentados tienen derecho a la ciudadanía. La segunda generación llega a 1.579.446 personas (1945-2015), el 67\% con ambos padres colombianos y el $33 \%$ con un padre colombiano; el $25,4 \%$ tiene una edad de 0 a 15 años, el 40,8\% de 16 a 35 años, el 21,3\% de 36 a 49 años y el 12,5\% 50 años o más. La edad media de la segunda generación es de 29 años, similar al promedio del total de la población venezolana. La tercera generación se puede estimar aplicando la tasa natural de

${ }^{10}$ Ver Sassen (1979), Díaz-B. y Frederick (1984), Pellegrino (1985), Aguilera (1994, pp. 25-38), Medina (2004), Lares (2005), AVN (2010), Queffelec (2010), Saavedra (2012) y Schwartz (2016).

${ }^{11}$ La partida de nacimiento incluye el país de origen de los padres y en muchos casos la región de procedencia. Por ejemplo, padre nacido en Italia, provincia de Milán, etc. 
crecimiento de la población venezolana a la segunda generación de colombianos, suponiendo que hay una convergencia en las tasas de natalidad y mortalidad. Su total llega a 885.358 personas, así que la comunidad binacional-bicultural alcanzaría 5.884 .544 personas; esta cifra comprende hijos de uniones o matrimonios mixtos que incluyen venezolanos y otros extranjeros residentes en Venezuela. No obstante, esta sería la comunidad con ciudadanía colombiana o con derecho a ella, y representa el 19\% de la población de Venezuela y el $12 \%$ de la de Colombia. Por cada persona nacida en Venezuela hay 0,86 con ancestros colombianos. En Estados Unidos, país de alta inmigración colombiana en la segunda mitad del siglo XX, la relación es de 0,64 con ancestros colombianos por un nacido, es decir, 653.000 de primera generación y 420.000 de segunda generación (López, 2015). E1 80\% tiene una edad de 15 a 64 años, y la edad mediana de la primera generación es de 45 años. La tasa de crecimiento promedio de la comunidad colombo-venezolana (saldos migratorios netos inter-censales más tasa de crecimiento natural), entre 1945 y 2015, es de $6,96 \%$, mientras que para el total de la población es de 2,82\%, es decir, 2,5 veces superior.

De las personas de segunda y tercera generación, posiblemente muy pocas gozan de ciudadanía colombiana, quizá un 5\%. De hecho, los colombianos de segunda generación, aparentemente, ingresan, en su mayoría, con su ciudadanía venezolana a territorio colombiano. En un sondeo $(\mathrm{N}=90)$ efectuado solo entre hijos de colombianos residenciados en Colombia que participan en redes sociales (Facebook) ${ }^{12}$, denominados venezolanos en Colombia -Bogotá, Bucaramanga, Barranquilla, La Guajira, Eje Cafetero, Antioquia, Manizales y Santa Marta-, el 10\% había solicitado el Permiso Especial de Permanencia, el 23,3\% tramitaba la ciudadanía colombiana y el 76,7\% aún no. Ante la pregunta de quiénes ya tenían el derecho a la ciudadanía colombiana $(\mathrm{N}=30)$ el 37,7\% contestó afirmativamente y el 63,3\% negativamente. Quizá muchos colombianos de segunda generación se encuentren en Colombia como ciudadanos venezolanos, situación explicable por la enorme dimensión de la comunidad, que se irá zanjando a medida que hagan el trámite respectivo.

\section{CRECIMIENTO ECONÓMICO COLOMBIANO, 1888-2013}

Si bien el tema de este escrito excluye un análisis minucioso de todas las variables relacionadas con el crecimiento económico y la historia

12 Realizado por el autor en septiembre de 2017.

Revista de Economía Institucional, vol. 2 i, N. ${ }^{\circ}$ 4O, enero-junio/20i9, Pp. 259 -289 ISSN OI 24-5996/E-ISSN 2346-2450 
económica colombiana ${ }^{13}$, el panorama se puede simplificar recurriendo como punto de referencia al comportamiento del sector externo. Cabe proponer tres etapas: 1) acumulación, despegue y consolidación del crecimiento, sujeto al desarrollo del sector cafetero, que cubre casi cien años; 2) desaceleración relativa a medida que las exportaciones de café pierden importancia, de finales de los años setenta a comienzos los años noventa; 3 ) expansión acelerada de la inversión y la producción en el sector minero-energético, especialmente en la primera década del siglo XXI. La gráfica 6 muestra la importancia del café y el petróleo en el sector externo colombiano en el largo plazo.

Las líneas se cruzan en los años 1992 a 1994, y en adelante el café entra en una declinación irreversible, mientras que las exportaciones de petróleo y derivados crecen paulatinamente, del 15,38\% en 1994 al 55,22\% en 2013, con respecto al total. Sumadas al carbón y otros minerales llegan al 80\% o algo más de las exportaciones totales.

\section{Gráfica 6}

Porcentaje de café y petróleo en el total de exportaciones, 1926-2013

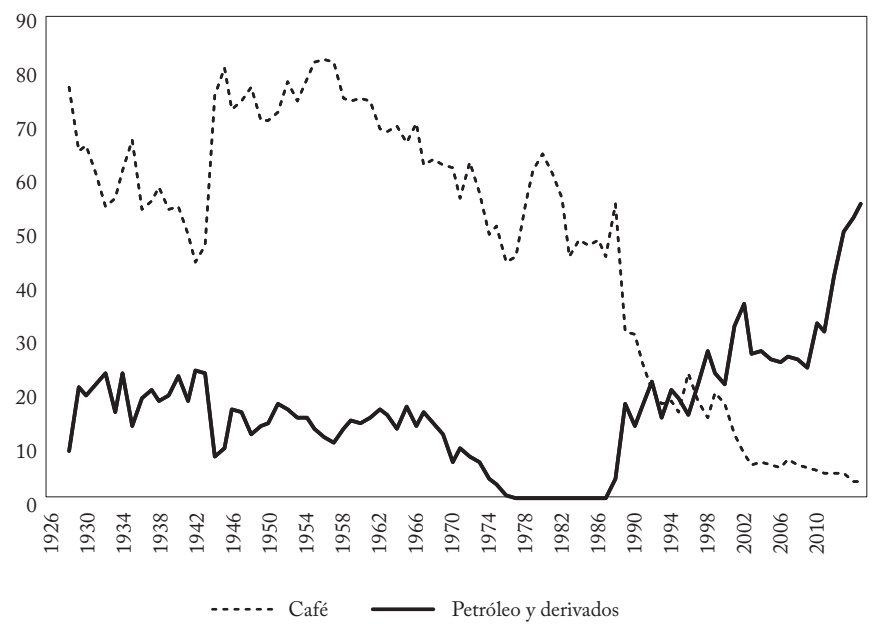

Fuente: Dane.

\section{ANTECEDENTES DEL CRECIMIENTO MODERNO}

En el siglo XIX, el crecimiento del producto colombiano posiblemente estuvo ligado estrechamente a la tasa de variación demográfica, aunque en algunas regiones -como Antioquia, Cundinamarca y Panamápudo haber ligeros aumentos de la productividad, si bien falta una confirmación cuantitativa sólida a este respecto. Era una economía

13 Ver Kalmanovitz (2010). 
archipiélago, como la del resto de América Latina, sin un mercado nacional bien integrado, en un país formado por regiones casi autárquicas, tanto desde el punto de vista económico como demográfico. Esta situación duraría hasta bien entrado el siglo XX. Debido a la concentración de la población en cordilleras abruptas, Colombia ha sido renuente a recibir flujos migratorios externos y ha presentado poca movilidad interna de sus habitantes. Una nación aislada física y culturalmente de sí misma y del resto del mundo por mucho tiempo.

La idea de progreso económico y su correlativo orden social estuvo signada por el debate-conflicto entre liberales y conservadores y sus diversas corrientes internas. Sin embargo, puede afirmarse que el periodo de predominio del liberalismo (1850-1886) trajo consigo, aunque con oscilaciones, dependiendo de los productos de exportación punteros (tabaco, añil, algodón o quina), diferentes al oro, rachas de crecimiento temporales. No obstante, se sentaron las bases del desarrollo de otros productos, como el café. Esta situación fue interrumpida por la reacción conservadora, bajo los varios gobiernos de La Regeneración, y se plasmó en la Constitución de 1886, que condujo a una fuerte caída del crecimiento económico y a tres guerras civiles (1884-1885, 1895 y la Guerra de los Mil Días, entre 1899-1902). Si se quisiera explicar sintéticamente el conflicto interno, se podría usar como referencia la biografía intelectual de Miguel Antonio Caro (1993). Caro fue un católico integrista e hispanófilo, que personificó en todo su esplendor las ideas de la reacción del partido nacionalista, en alianzas con sectores de los partidos históricos (conservadores y liberales). Caro fue vicepresidente de Rafael Núñez en 1892 y presidente entre 1892-1898 (si bien le gustaba llamarse vicepresidente encargado), y elaboró un proyecto de país centralista, nacional-católico, estatista y anticapitalista. Un hombre de gran cultura y pensamiento ecléctico, pero anclado en una concepción confesional-corporativa de la sociedad, y enemigo acérrimo del utilitarismo de Bentham y del liberalismo de inspiración anglosajona. En el ámbito económico, restableció el monopolio estatal sobre el estanco del tabaco, gravó las exportaciones de café (1895) y apoyó la creación de dinero fiduciario, a través del Banco Nacional, que no actuaba precisamente como banco central, sino como un financista del gobierno. Frente a esta concepción, el liberalismo colombiano, en su expresión más refinada, mantuvo un ideario, aunque no libre de contradicciones, apegado al desarrollo económico manchesteriano (laissez faire) y al anticlericalismo, así como a un gobierno delimitado y federal que defendiera las libertades individuales. 
Estas dos visiones antagónicas del mundo chocaron con ímpetu feroz a finales del siglo XIX y desembocaron en la Guerra de los Mil Días, que costó a la nación unos 39.000 muertos (Meisel y Romero, 2017). La guerra entre los partidos conservador y liberal desalojó del poder a los nacionalistas, dejó una secuela de destrucción y la pérdida del Estado Soberano de Panamá. Durante esos años la economía sufrió un retroceso sustancial; quizá en su mejor momento, durante el periodo liberal, el ingreso per cápita llegó a 950-1.000 dólares de 1990, y desde 1886 retrocedió hasta llegar a 786 dólares en 1901. E1 fin de la guerra, en la que vencieron los conservadores, trajo consigo, sin embargo, acuerdos mínimos de convivencia entre la élite en el poder, que apalancaron la estabilidad institucional y el posterior progreso económico.

\section{CRECIMIENTO INTENSIVO}

En la primera década del siglo XX se inicia la fase de crecimiento moderno acoplado a la expansión del sector externo, básicamente a la producción de café, que será el producto de exportación determinante durante gran parte del siglo XX. El crecimiento económico intensivo se consolida durante los años veinte. La oferta de café colombiano suplió el 1\% de la demanda global entre 1875-1885; en 1930 llegaba al 12\%, solo detrás de Brasil. Cuatro macro-factores concurrirán en este desarrollo: el aumento del coeficiente de comercio exterior en relación al PIB, es decir, un incremento de las exportaciones (café) e importaciones, la inversión en infraestructuras, que acompaña y facilita el desarrollo del sector externo, la ampliación del sector manufacturero ligero (textiles) y la importación de capital extranjero, por diversas vías: endeudamiento (prosperidad a debe), inversiones directas y el pago de 25 millones de dólares, por Estados Unidos, como indemnización por la secesión de Panamá (tratado Thompson-Urrutia de 1914). La combinación de esos elementos estimula la inversión y el crecimiento moderno. Las gráficas 7, 8, 9 y 10 resumen algunas estadísticas que ayudan a entender el despegue económico.

Como se observa en las gráficas, los años veinte son decisivos para el proceso de crecimiento intensivo. Todas las variables revelan un importante aumento de la actividad económica (la inversión se multiplica 2,6 veces entre 1910 y 1928). Con el estallido de la Gran Depresión de 1929, la adopción de políticas proteccionistas y la Segunda Guerra Mundial, el crecimiento económico se desacelera y se hace más volátil. Y con el fin de la guerra y el establecimiento de 


\section{Gráfica 7}

Índice de comercio exterior, 1905-1940

$1905=100$

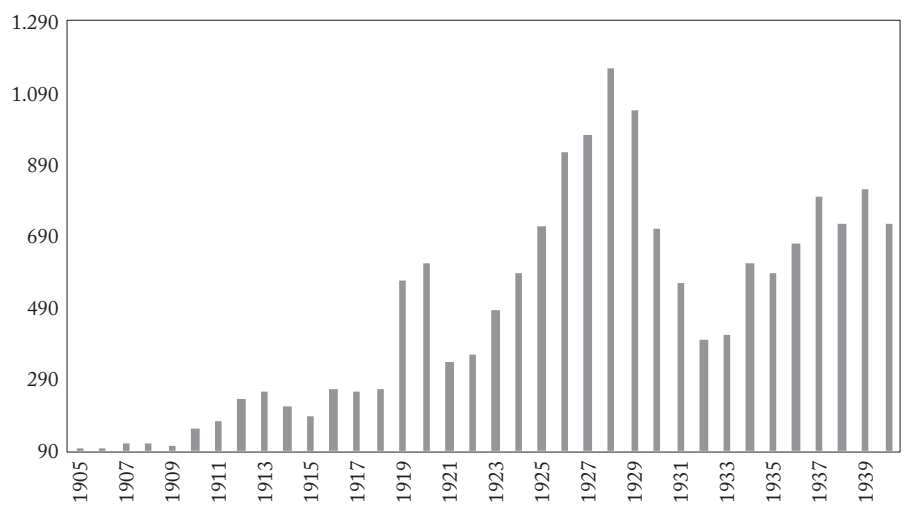

Fuente: Banrep-Greco.

Gráfica 8

Índice del gasto de ministerios en obras públicas como porcentaje del total $1920=100$

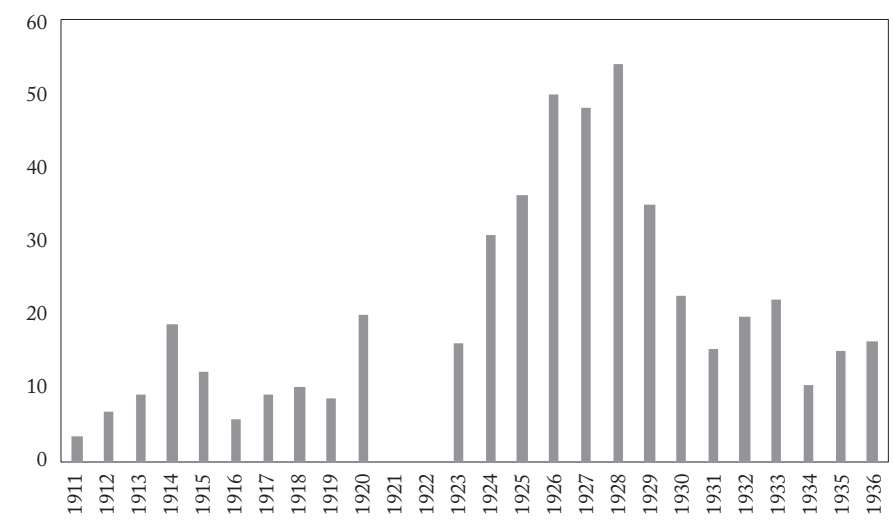

Fuente: Tovar (1984).

un nuevo orden mundial bipolar, la economía retoma la progresión pausada, vinculada a la producción y exportación de café.

Vista en el muy el largo plazo, la economía colombiana mostrará las características mencionadas: una tasa de crecimiento moderada asociada a una aparente baja volatilidad. Los métodos para analizar series de tiempo son múltiples, pero se emplea una media móvil de 10 años para ver el desempeño del ingreso per cápita y el producto, que se presentan en las gráficas 10 a 12 . 
Gráfica 9

Índice de la deuda externa 1920-1936

$1920=100$

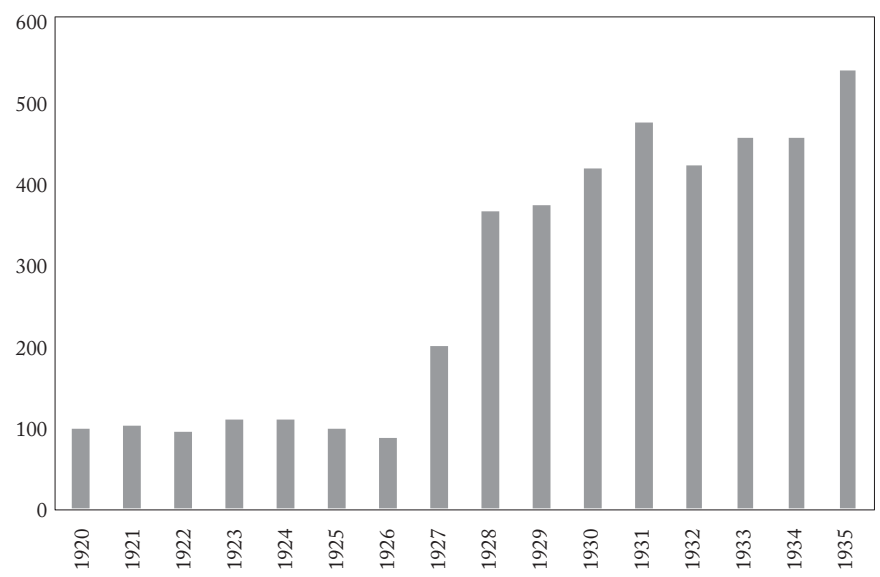

Fuente: Tovar (1984).

Gráfica 10

FBKF como porcentaje del PIB, 1888-1940

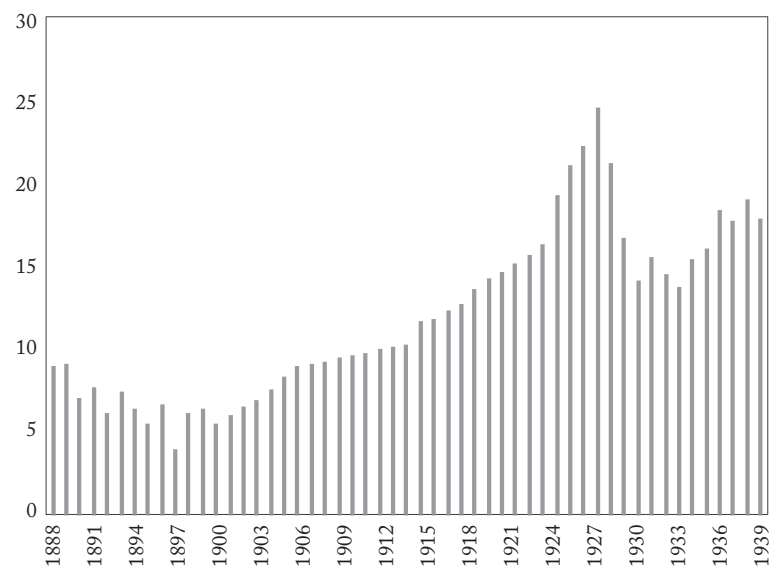

Fuente: Dane, cálculos propios; ver sección sobre el método.

Los picos de mayor altura en el incremento del ingreso real per cápita ocurren en los años setenta del siglo XX y en la primera década del siglo XXI. De la gráfica 11 se debe resaltar que el ciclo mineroenergético impulsó un alza sostenida del ingreso real per cápita, donde se retroalimentan la exportación de petróleo y otros minerales y las 


\section{Gráfica 11}

Crecimiento del PIB per cápita a precios de 1975, 1888-2013

(Porcentaje de la media móvil de 10 años)

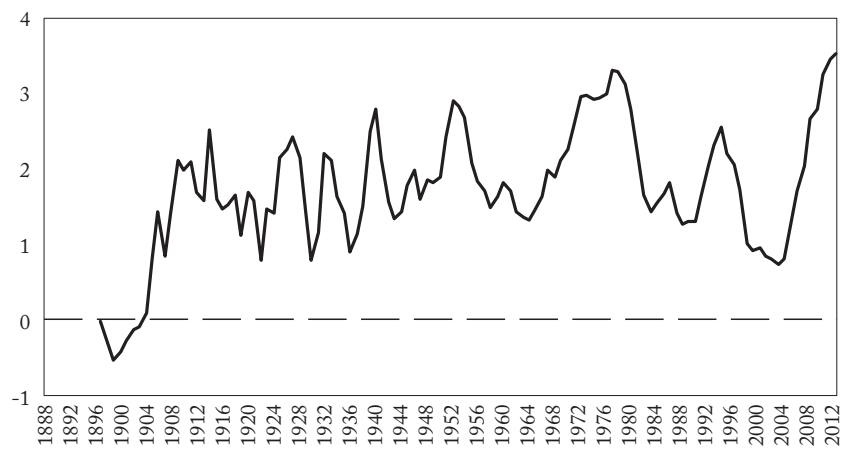

Fuente: Dane, cálculos propios.

\section{Gráfica 12}

Crecimiento del PIB a precios de 1975, 1888-2013

(Porcentaje de la media móvil de 10 años)

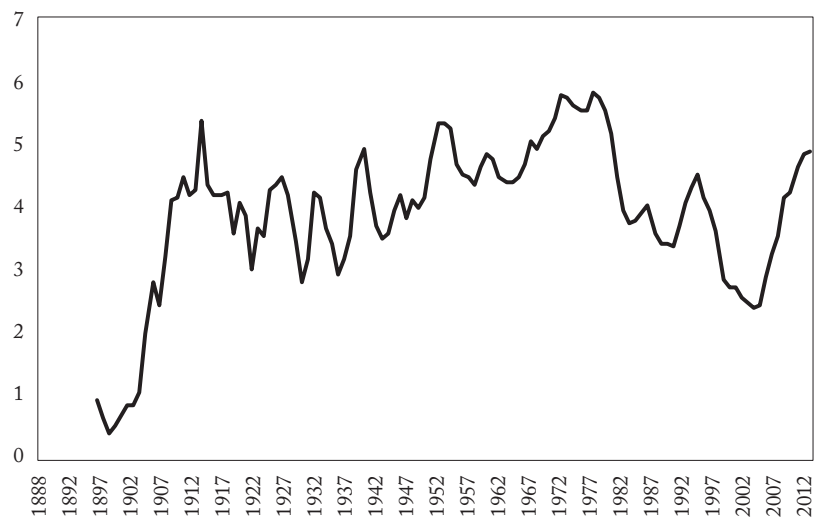

Fuente: Dane, cálculos propios.

inversiones extranjeras que atraen estos sectores, generando un efecto multiplicador en el resto de la economía.

Es evidente, como muestran las gráficas anteriores, que el desarrollo del sector extractivo sacó a la economía colombiana de la difícil hacia la que se encaminaba, pues mientras que disminuía la importancia del café (el principal producto de exportación), la oferta exportable de bienes no tradicionales y la inversión eran insuficientes para dinamizar la economía. E1 crecimiento, que se desacelera poco a poco desde finales de los setenta, se recobra y robustece a medida que la 
oferta de bienes exportables se modifica gradualmente y el perfil de la economía se torna cada vez más minero-extractivista.

En el plano histórico cualitativo, lo sucedido en la primera década de este siglo no es casual, es resultado de la confluencia de varios componentes que en cierto modo repiten lo acontecido en los años veinte del siglo pasado. Nuevamente se produce una fuerte expansión del sector externo, gracias al cuantioso incremento de las exportaciones del sector minero-energético, asociadas al crecimiento de la economía global. De igual manera, la inversión extranjera aumenta por varias razones, como la apertura entusiasta al capital foráneo, los mayores niveles de seguridad pública, alcanzados con la política de seguridad democrática y el apoyo militar y financiero de Estados Unidos, y finalmente las mejoras de la infraestructura. Estos factores concurrirán en el desarrollo de un nuevo ciclo ascendente de exportación de materias primas. Y así como en el primer ciclo predominó el café, en el segundo predominan el petróleo y el carbón.

Sin lugar a dudas, Colombia ha experimentado un auge petrominero en los últimos 15 años, con expansión del consumo de bienes importados y rápido crecimiento del sector de bienes no transables. Este desarrollo se ha concentrado especialmente en las grandes urbes -Bogotá, Medellín Barranquilla y Cartagena, entre otras- y deja por fuera amplios espacios geoeconómicos como la frontera oriental y el Pacífico. El petróleo y la minería, como ayer el café, estimulan el crecimiento y la modernización, aunque en esta oportunidad el oro negro introduce una variante: concede un poder de compra adicional, por encima de la capacidad efectiva para generar riqueza de la economía colombiana, es decir, una renta internacional que crea una sensación general de bienestar concomitante con la relativa expansión de los sectores medios de la sociedad y el consumo de bienes y servicios modernos. Se trata de la pauta usual del modelo económico basado en la captura de rentas mineras internacionales. Pero, a diferencia del café, la prosperidad minera tiene riesgos: se basa en industrias intensivas en capital, que generan pocos empleos y dañan el ambiente, al tiempo que los choques de precios externos tienen amplias repercusiones negativas en el desempeño económico y volatilizan su comportamiento. La mayor debilidad de este modelo de crecimiento es el nivel de reservas probadas de petróleo (7 años), escasas para mantener una producción de algo más de 1 millón de barriles diarios en el largo plazo. De hecho, la tasa máxima de extracción de petróleo, en torno a 1,2 millones de barriles diarios, se podría alcanzar en 2018-2019, si no se descubren nuevos campos 
importantes, y a partir de ahí sobrevendría el declive terminal, es decir, un pico petrolero o curva de Hubbert prematura.

Si bien no hay un cálculo oficial del PIB petrolero, la ANDI estimó el PIB minero-energético (petróleo, gas, minerales metálicos, minerales no metálicos, carbón y electricidad); según esos datos, el petróleo pasó de representar el 4\% del PIB en 2000 al 9\% en 2012, mientras que el PIB minero-energético total se elevó del $8 \%$ al 14,8\% del PIB.

Las gráficas 13 a 15 muestran que el petróleo se ha convertido en el centro de gravedad de la economía colombiana en los últimos años. No obstante, cabe enfatizar que la colombiana no es una economía petrolera que se pueda calificar como petro-dependiente.

\section{Gráfica 13}

Exportaciones petroleras y todas las demás

(Miles de millones de dólares, 1992 = 100)

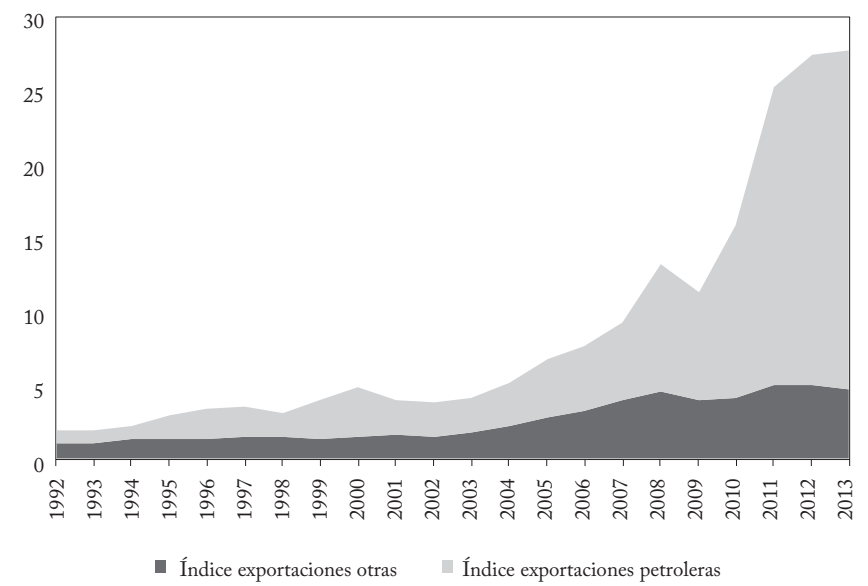

Fuente: Dane, cálculos propios.

En términos generales, la nación andina ha consumado una ruptura estructural con su pasado, transitando de una economía basada en la agricultura de exportación y la industria ligera a una economía extractiva, con un veloz desarrollo del sector terciario (finanzas y construcción) en la segunda década de este siglo. Sin embargo, el buen desempeño de las tasas de crecimiento de la última década no parece viable en el largo plazo, en vista de la debilidad intrínseca del verdadero motor de este engranaje que es la industria de los hidrocarburos. Todo dependerá del precio del petróleo en el mercado internacional y del azar, es decir, del descubrimiento de nuevos yacimientos para sostener la producción y exportación en el futuro o de la introducción del fracking. 
Gráfica 14

Exportaciones petroleras como porcentaje del total 1992-2013

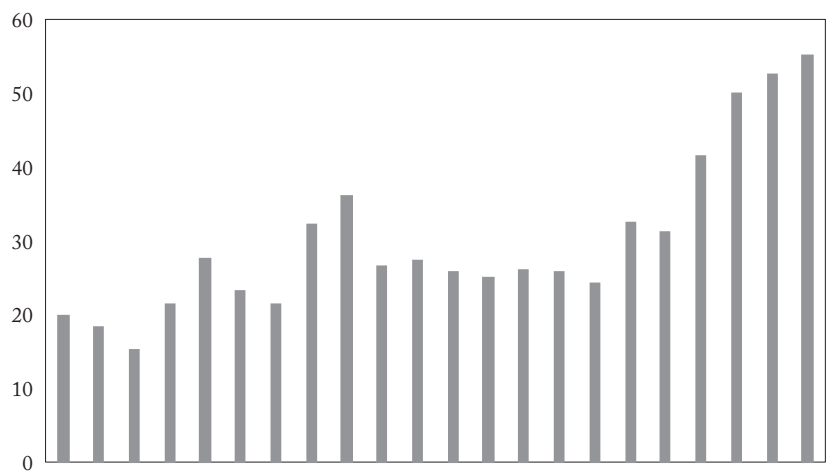

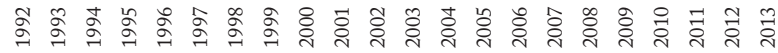
Fuente: Dane.

Gráfica 15

Reservas petroleras colombianas/Producción

(Número de años)

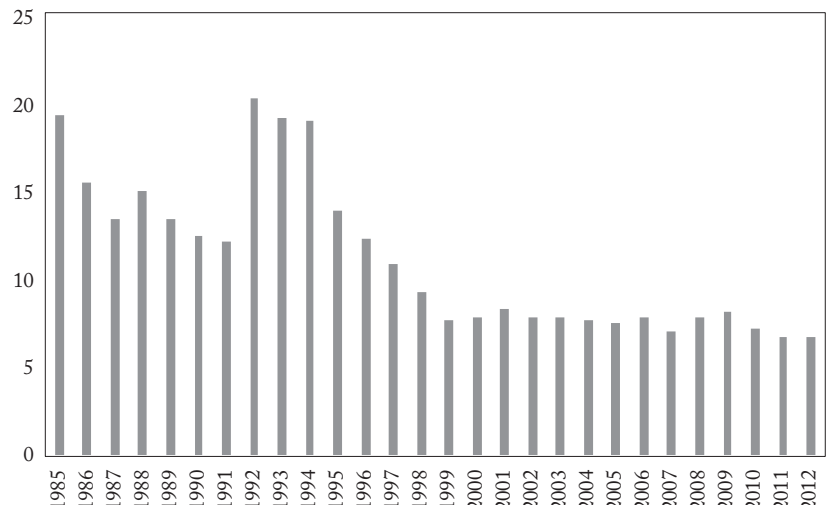

Fuente: Sistema de información y Gas colombiano.

Las exportaciones totales colombianas se multiplicaron por 8 entre 1992 y 2013, pero la aceleración fue muy superior en el sector petrolero, cuyo coeficiente es de 23 , mientras que en el resto de los bienes exportados es de 4,6. E1 porcentaje de las exportaciones petroleras en el total fluctuó en el periodo 1992-2009, con un promedio del 26\%, pero desde 2010 se ha consolidado rápidamente como el principal rubro de comercialización externa, hasta llegar al 55\% de las exportaciones totales en 2013.

La firma de los tratados de libre comercio, como alternativa al sector minero-energético, es por ahora una panacea, porque la oferta 
exportable del país es insuficiente en contenido tecnológico, diseño y calidad, y la infraestructura aún está sumamente retrasada, lo que incrementa los costos de transporte de las mercancías e impone limitaciones objetivas cuya superación requiere largo tiempo y fondos cuantiosos. Las inversiones extranjeras pueden ser y han sido un importante estímulo del crecimiento en la última década, pero están condicionadas, en última instancia, por el desarrollo del sector minero-energético.

\section{COMPARACIÓN CON OTRAS SERIES HISTÓRICAS}

Básicamente existen 4 series de la economía colombiana: las de Cepal-Dane, Banrep-Greco, Moxlad y Maddison y, además, la que aquí llamamos De Corso (ver anexo). Así mismo se corresponden con fechas diversas, pues Cepal-Dane va desde 1925 hasta hoy, BanrepGreco cubre 1905-2000, Moxlad 1900-2010 y De Corso 1888-2013. En lo que respecta a los precios, Banrep-Greco se expresa en pesos de 1975 y corrientes, Moxlad en precios corrientes, pesos de 1970 y dólares de paridad de compra de 1970 y 1990, y Cepal-Dane en diversas bases $(1975,1994,2000,2005)$. Por último, la serie que aquí se propone se expresa en precios corrientes, pesos constantes de 1975 y dólares internacionales de 1990 y 2011. En el cuadro 2 se presentan las distintas tasas de crecimiento según las series mencionadas.

Cuadro 2

Comparación de diversas series del PIB

\begin{tabular}{lccc}
\hline Serie & Años & PIB & PIB per cápita \\
\hline Maddison & $1900-1929$ & 3,39 & 1,56 \\
De Corso & $1900-1929$ & 3,72 & 1,71 \\
Moxlad & $1900-1929$ & 4,97 & 2,98 \\
Banrep-Greco & $1905-1929$ & 5,75 & 3,70 \\
Maddison & $1900-2008$ & 4,09 & 1,78 \\
De Corso & $1900-2008$ & 4,08 & 1,83 \\
Moxlad & $1900-2010$ & 4,39 & 2,16 \\
De Corso & $1900-2010$ & 4,06 & 1,84 \\
Banrep-Greco & $1905-2000$ & 4,56 & 2,33 \\
De Corso & $1905-2000$ & 4,18 & 1,81 \\
Dane & $1925-2012$ & 4,25 & 2,03 \\
De Corso & $1925-2012$ & 4,26 & 2,04 \\
Dane & $2000-2012$ & 4,32 & 3,14 \\
De Corso & $2000-2012$ & 4,31 & 2,87 \\
De Corso & $1888-2013$ & 3,78 & 1,69 \\
\hline
\end{tabular}

Fuentes: Maddison, Moxlad, Banrep-Greco, Dane y De Corso. 


\section{CONCLUSIONES}

Para estimar la serie que se presenta en este trabajo se empleó una metodología rigurosa que, empleando la mejor información disponible, reconstruyó año por año, de 1888 a 1929 los componentes del PIB (consumo, inversiones, gasto público y sector externo). La serie estimada, empalmada con las cifras oficiales, constituye una serie de largo plazo del producto de la economía colombiana razonable y útil para la investigación histórico-económica. La serie de población es más precisa gracias al exhaustivo trabajo cuantitativo de Yáñez, Rivero et al. (2012), que no se limita a Colombia sino que incluye 21 países de América Latina. Las cifras resultantes indican que el crecimiento del ingreso per cápita ha sido pausado pero constante y que el ingreso se multiplicó por 7 entre 1888 y 2013 (con un margen de error del 5\%). El crecimiento económico moderno del país se inició a comienzos del siglo XX, asociado a la integración a la economía global a través de la producción y las exportaciones de café. El desarrollo del sector minero-energético dio lugar a un ciclo de mayor prosperidad y fuerte crecimiento basado en la exportación de petróleo, la principal fuente de energía en el mundo de hoy en día.

No obstante, el futuro del crecimiento de la economía colombiana luce frágil, pues enfrenta desafíos formidables. En primer lugar, ¿cómo sostener la producción y exportación de petróleo, para evitar que en un corto periodo se convierta en importador neto? Este desafío supone la introducción masiva del fracking como método o técnica de extracción (GIR, 2018), con las consecuencias ambientales y los posibles conflictos sociales que pueda suscitar. En segundo lugar, es preciso enfrentar el impacto demográfico debido a la accidentada transición venezolana de una economía petrolera a una post-petrolera, que genera una superpoblación, en gran parte de origen extranjero, que no puede integrar ni atender el Estado venezolano como en otros tiempos, con el reparto de subsidios y auxilios provenientes de la renta petrolera. Ese impacto no provendrá de la inmigración temporal y transitoria, pues la mayoría de los venezolanos salen del territorio colombiano hacia otros destinos o regresan a su país de origen. Puede ser causado más bien por un explosivo traslado de los más de 5 millones de nacidos en Colombia y de sus descendientes de varias generaciones que viven en Venezuela, cuya primera opción, y la más natural, para huir de la crisis es retornar al lugar ancestral de origen. En la segunda generación, de la cual se tienen datos fidedignos, hay más de un millón y medio de personas debidamente registradas, a las que se sumaría un número 
indeterminado de personas no registradas (por descuido de sus padres o por problemas en las jefaturas civiles). ¿Cuál es la capacidad de la economía colombiana y el grado de tolerancia de su sociedad para albergar e integrar a sus connacionales retornados? Y, ¿qué tan capaz es el orden socio-político para crear consensos alrededor del fracking? Son temas abiertos al debate y al análisis, pero que tendrán gran incidencia en el desempeño futuro de la economía colombiana.

\section{ANEXOS}

Cuadro A1

PIB de Colombia, 1888-2013

\begin{tabular}{|c|c|c|c|c|c|c|c|c|}
\hline Años & $\begin{array}{l}\text { Población } \\
\text { (Miles) }\end{array}$ & $\begin{array}{c}\text { PIB } \\
\text { (Pesos } \\
\text { corrientes) }\end{array}$ & $\begin{array}{c}\text { Deflactor } \\
\text { (Base: 1975) }\end{array}$ & $\begin{array}{c}\text { PIB } \\
\text { (Millones, } \\
\text { pesos de } \\
1975 \text { ) }\end{array}$ & $\begin{array}{l}\text { PIB per } \\
\text { cápita } \\
\text { (Pesos de } \\
1975 \text { ) }\end{array}$ & $\begin{array}{c}\text { PIB per } \\
\text { cápita } \\
\text { (Dólares } \\
\text { de 1990) }\end{array}$ & $\begin{array}{c}\text { PIB per } \\
\text { cápita } \\
\text { (Dólares } \\
\text { de 2011) }\end{array}$ & Índice \\
\hline 1888 & 3.935 & 179 & 1,0345 & 17.314 & 4.400 & 875 & 1.485 & 1,00 \\
\hline 1889 & 3.973 & 180 & 1,0406 & 17.265 & 4.346 & 864 & 1.466 & 0,99 \\
\hline 1890 & 4.012 & 161 & 0,9441 & 17.033 & 4.246 & 844 & 1.432 & 0,96 \\
\hline 1891 & 4.051 & 153 & 0,9118 & 16.820 & 4.152 & 826 & 1.401 & 0,94 \\
\hline 1892 & 4.091 & 166 & 0,9858 & 16.848 & 4.118 & 819 & 1.389 & 0,94 \\
\hline 1893 & 4.131 & 172 & 0,9700 & 17.703 & 4.285 & 852 & 1.446 & 0,97 \\
\hline 1894 & 4.171 & 155 & 0,8523 & 18.144 & 4.350 & 865 & 1.468 & 0,99 \\
\hline 1895 & 4.211 & 146 & 0,8337 & 17.546 & 4.167 & 829 & 1.406 & 0,95 \\
\hline 1896 & 4.252 & 149 & 0,8351 & 17.810 & 4.189 & 833 & 1.413 & 0,95 \\
\hline 1897 & 4.294 & 179 & 1,0065 & 17.747 & 4.133 & 822 & 1.394 & 0,94 \\
\hline 1898 & 4.336 & 160 & 0,8440 & 18.953 & 4.371 & 869 & 1.475 & 0,99 \\
\hline 1899 & 4.378 & 153 & 0,8333 & 18.349 & 4.191 & 833 & 1.414 & 0,95 \\
\hline 1900 & 4.421 & 157 & 0,8862 & 17.679 & 3.999 & 795 & 1.349 & 0,91 \\
\hline 1901 & 4.464 & 153 & 0,8658 & 17.651 & 3.954 & 786 & 1.334 & 0,90 \\
\hline 1902 & 4.507 & 153 & 0,8534 & 17.966 & 3.986 & 793 & 1.345 & 0,91 \\
\hline 1903 & 4.551 & 168 & 0,8787 & 19.147 & 4.207 & 837 & 1.419 & 0,96 \\
\hline 1904 & 4.595 & 179 & 0,9103 & 19.663 & 4.279 & 851 & 1.444 & 0,97 \\
\hline 1905 & 4.640 & 174 & 0,8987 & 19.384 & 4.177 & 831 & 1.409 & 0,95 \\
\hline 1906 & 4.776 & 170 & 0,7908 & 21.510 & 4.504 & 896 & 1.520 & 1,02 \\
\hline 1907 & 4.916 & 172 & 0,7425 & 23.202 & 4.720 & 938 & 1.592 & 1,07 \\
\hline 1908 & 5.060 & 177 & 0,7433 & 23.872 & 4.718 & 938 & 1.592 & 1,07 \\
\hline 1909 & 5.208 & 234 & 0,9367 & 24.965 & 4.794 & 953 & 1.617 & 1,09 \\
\hline 1910 & 5.361 & 230 & 0,8739 & 26.295 & 4.905 & 975 & 1.655 & 1,11 \\
\hline 1911 & 5.518 & 218 & 0,8240 & 26.401 & 4.784 & 951 & 1.614 & 1,09 \\
\hline 1912 & 5.679 & 255 & 0,9217 & 27.719 & 4.881 & 971 & 1.647 & 1,11 \\
\hline 1913 & 5.817 & 287 & 0,9980 & 28.789 & 4.949 & 984 & 1.670 & 1,12 \\
\hline 1914 & 5.958 & 329 & 1,1093 & 29.689 & 4.983 & 991 & 1.681 & 1,13 \\
\hline 1915 & 6.102 & 368 & 1,1323 & 32.517 & 5.329 & 1.060 & 1.798 & 1,21 \\
\hline 1916 & 6.250 & 367 & 1,1170 & 32.844 & 5.255 & 1.045 & 1.773 & 1,19 \\
\hline 1917 & 6.402 & 403 & 1,1565 & 34.860 & 5.445 & 1.083 & 1.837 & 1,24 \\
\hline 1918 & 6.557 & 504 & 1,4055 & 35.859 & 5.469 & 1.087 & 1.845 & 1,24 \\
\hline 1919 & 6.688 & 557 & 1,4791 & 37.651 & 5.630 & 1.119 & 1.899 & 1,28 \\
\hline 1920 & 6.822 & 536 & 1,4395 & 37.254 & 5.461 & 1.086 & 1.842 & 1,24 \\
\hline 1921 & 6.958 & 603 & 1,5379 & 39.193 & 5.633 & 1.120 & 1.900 & 1,28 \\
\hline 1922 & 7.097 & 590 & 1,4618 & 40.352 & 5.686 & 1.131 & 1.918 & 1,29 \\
\hline 1923 & 7.240 & 560 & 1,4543 & 38.478 & 5.315 & 1.057 & 1.793 & 1,21 \\
\hline 1924 & 7.384 & 594 & 1,4060 & 42.240 & 5.720 & 1.137 & 1.930 & 1,30 \\
\hline 1925 & 7.532 & 570 & 1,2462 & 45.771 & 6.077 & 1.208 & 2.050 & 1,38 \\
\hline 1926 & 7.683 & 713 & 1,4396 & 49.509 & 6.444 & 1.281 & 2.174 & 1,46 \\
\hline 1927 & 7.837 & 704 & 1,3310 & 52.864 & 6.745 & 1.341 & 2.276 & 1,53 \\
\hline 1928 & 7.993 & 714 & 1,2978 & 55.013 & 6.883 & 1.369 & 2.322 & 1,56 \\
\hline 1929 & 8.153 & 899 & 1,5972 & 56.255 & 6.900 & 1.372 & 2.328 & 1,57 \\
\hline 1930 & 8.317 & 744 & 1,4397 & 51.678 & 6.214 & 1.236 & 2.096 & 1,41 \\
\hline 1931 & 8.483 & 590 & 1,1597 & 50.874 & 5.997 & 1.192 & 2.023 & 1,36 \\
\hline
\end{tabular}




\begin{tabular}{|c|c|c|c|c|c|c|c|c|}
\hline Años & $\begin{array}{l}\text { Población } \\
\text { (Miles) }\end{array}$ & $\begin{array}{c}\text { PIB } \\
\text { (Pesos } \\
\text { corrientes) }\end{array}$ & $\begin{array}{c}\text { Deflactor } \\
\text { (Base: 1975) }\end{array}$ & $\begin{array}{c}\text { PIB } \\
\text { (Millones, } \\
\text { pesos de } \\
1975 \text { ) }\end{array}$ & $\begin{array}{l}\text { PIB per } \\
\text { cápita } \\
\text { (Pesos de } \\
1975)\end{array}$ & $\begin{array}{l}\text { PIB per } \\
\text { cápita } \\
\text { (Dólares } \\
\text { de 1990) }\end{array}$ & $\begin{array}{l}\text { PIB per } \\
\text { cápita } \\
\text { (Dólares } \\
\text { de 2011) }\end{array}$ & Índice \\
\hline 1932 & 8.653 & 529 & 0,9739 & 54.320 & 6.278 & 1.248 & 2.118 & 1,43 \\
\hline 1933 & 8.826 & 575 & 0,9987 & 57.575 & 6.523 & 1.297 & 2.201 & 1,48 \\
\hline 1934 & 9.002 & 849 & 1,3561 & 62.605 & 6.955 & 1.383 & 2.346 & 1,58 \\
\hline 1935 & 9.183 & 901 & 1,3881 & 64.908 & 7.068 & 1.405 & 2.385 & 1,61 \\
\hline 1936 & 9.366 & 1.003 & 1,4599 & 68.705 & 7.336 & 1.459 & 2.475 & 1,67 \\
\hline 1937 & 9.554 & 1.049 & 1,5034 & 69.777 & 7.303 & 1.452 & 2.464 & 1,66 \\
\hline 1938 & 9.745 & 1.256 & 1,6900 & 74.319 & 7.626 & 1.516 & 2.573 & 1,73 \\
\hline 1939 & 9.959 & 1.379 & 1,7483 & 78.875 & 7.920 & 1.575 & 2.672 & 1,80 \\
\hline 1940 & 10.179 & 1.430 & 1,7747 & 80.579 & 7.916 & 1.574 & 2.671 & 1,80 \\
\hline 1941 & 10.402 & 1.397 & 1,7051 & 81.932 & 7.877 & 1.566 & 2.658 & 1,79 \\
\hline 1942 & 10.631 & 1.532 & 1,8659 & 82.104 & 7.723 & 1.536 & 2.606 & 1,76 \\
\hline 1943 & 10.865 & 1.818 & 2,2052 & 82.441 & 7.588 & 1.509 & 2.560 & 1,72 \\
\hline 1944 & 11.104 & 2.233 & 2,5371 & 88.014 & 7.926 & 1.576 & 2.674 & 1,80 \\
\hline 1945 & 11.349 & 2.799 & 3,0377 & 92.142 & 8.119 & 1.614 & 2.739 & 1,85 \\
\hline 1946 & 11.598 & 3.332 & 3,2991 & 100.997 & 8.708 & 1.732 & 2.938 & 1,98 \\
\hline 1947 & 11.854 & 4.015 & 3,8269 & 104.916 & 8.851 & 1.760 & 2.986 & 2,01 \\
\hline 1948 & 12.115 & 4.704 & 4,3602 & 107.885 & 8.905 & 1.771 & 3.005 & 2,02 \\
\hline 1949 & 12.381 & 5.509 & 4,6955 & 117.324 & 9.476 & 1.884 & 3.197 & 2,15 \\
\hline 1950 & 12.568 & 7.860 & 6,6265 & 118.615 & 9.438 & 1.877 & 3.184 & 2,15 \\
\hline 1951 & 12.932 & 8.941 & 7,3098 & 122.316 & 9.458 & 1.881 & 3.191 & 2,15 \\
\hline 1952 & 13.309 & 9.651 & 7,4219 & 130.034 & 9.770 & 1.943 & 3.296 & 2,22 \\
\hline 1953 & 13.699 & 10.735 & 7,7824 & 137.940 & 10.069 & 2.002 & 3.397 & 2,29 \\
\hline 1954 & 14.113 & 12.759 & 8,6510 & 147.486 & 10.450 & 2.078 & 3.526 & 2,38 \\
\hline 1955 & 14.526 & 13.250 & 8,6459 & 153.252 & 10.550 & 2.098 & 3.560 & 2,40 \\
\hline 1956 & 14.957 & 14.863 & 9,3200 & 159.474 & 10.662 & 2.120 & 3.597 & 2,42 \\
\hline 1957 & 15.405 & 17.811 & 10,9249 & 163.031 & 10.583 & 2.104 & 3.571 & 2,41 \\
\hline 1958 & 15.868 & 20.682 & 12,3814 & 167.041 & 10.527 & 2.093 & 3.552 & 2,39 \\
\hline 1959 & 16.346 & 23.649 & 13,2030 & 179.118 & 10.958 & 2.179 & 3.697 & 2,49 \\
\hline 1960 & 16.841 & 26.747 & 14,3211 & 186.767 & 11.090 & 2.205 & 3.742 & 2,52 \\
\hline 1961 & 17.355 & 30.421 & 15,4993 & 196.273 & 11.309 & 2.249 & 3.816 & 2,57 \\
\hline 1962 & 17.887 & 34.199 & 16,5300 & 206.891 & 11.567 & 2.300 & 3.902 & 2,63 \\
\hline 1963 & 18.433 & 43.526 & 20,3680 & 213.698 & 11.593 & 2.305 & 3.911 & 2,63 \\
\hline 1964 & 18.990 & 53.760 & 23,6950 & 226.883 & 11.947 & 2.376 & 4.031 & 2,72 \\
\hline 1965 & 19.554 & 60.488 & 25,7340 & 235.051 & 12.021 & 2.390 & 4.056 & 2,73 \\
\hline 1966 & 20.131 & 73.285 & 29,6269 & 247.360 & 12.288 & 2.443 & 4.146 & 2,79 \\
\hline 1967 & 20.723 & 84.504 & 32,8059 & 257.588 & 12.430 & 2.472 & 4.194 & 2,83 \\
\hline 1968 & 21.321 & 97.102 & 35,5853 & 272.871 & 12.798 & 2.545 & 4.318 & 2,91 \\
\hline 1969 & 21.917 & 111.728 & 38,5904 & 289.523 & 13.210 & 2.627 & 4.457 & 3,00 \\
\hline 1970 & 22.500 & 132.768 & 43,1771 & 307.496 & 13.666 & 2.717 & 4.611 & 3,11 \\
\hline 1971 & 23.066 & 155.886 & 47,8435 & 325.825 & 14.126 & 2.809 & 4.766 & 3,21 \\
\hline 1972 & 23.619 & 189.614 & 54,0499 & 350.813 & 14.853 & 2.953 & 5.011 & 3,38 \\
\hline 1973 & 24.170 & 243.560 & 65,0538 & 374.398 & 15.490 & 3.080 & 5.226 & 3,52 \\
\hline 1974 & 24.728 & 322.384 & 81,4286 & 395.910 & 16.011 & 3.184 & 5.402 & 3,64 \\
\hline 1975 & 25.302 & 405.108 & 100,0000 & 405.108 & 16.011 & 3.184 & 5.402 & 3,64 \\
\hline 1976 & 25.894 & 532.270 & 125,4576 & 424.263 & 16.385 & 3.258 & 5.528 & 3,72 \\
\hline 1977 & 26.498 & 716.029 & 162,0320 & 441.906 & 16.677 & 3.316 & 5.627 & 3,79 \\
\hline 1978 & 27.111 & 909.487 & 189,7393 & 479.335 & 17.680 & 3.516 & 5.965 & 4,02 \\
\hline 1979 & 27.731 & 1.188 .817 & 235,3538 & 505.119 & 18.215 & 3.622 & 6.146 & 4,14 \\
\hline 1980 & 28.356 & 1.579 .130 & 300,3490 & 525.765 & 18.542 & 3.687 & 6.256 & 4,21 \\
\hline 1981 & 28.986 & 1.982 .773 & 368,7261 & 537.736 & 18.552 & 3.689 & 6.259 & 4,22 \\
\hline 1982 & 29.623 & 2.497 .298 & 460,0465 & 542.836 & 18.325 & 3.644 & 6.183 & 4,16 \\
\hline 1983 & 30.266 & 3.054 .137 & 553,9078 & 551.380 & 18.218 & 3.622 & 6.147 & 4,14 \\
\hline 1984 & 30.913 & 3.856 .584 & 676,7658 & 569.855 & 18.434 & 3.665 & 6.220 & 4,19 \\
\hline 1985 & 31.564 & 4.965 .883 & 845,1689 & 587.561 & 18.615 & 3.701 & 6.281 & 4,23 \\
\hline 1986 & 32.218 & 6.787 .956 & $1.091,6956$ & 621.781 & 19.299 & 3.837 & 6.511 & 4,39 \\
\hline 1987 & 32.877 & 8.824 .408 & $1.346,9006$ & 655.164 & 19.928 & 3.962 & 6.724 & 4,53 \\
\hline 1988 & 33.540 & 11.731 .348 & $1.720,6663$ & 681.791 & 20.328 & 4.042 & 6.858 & 4,62 \\
\hline 1989 & 34.206 & 15.126 .718 & $2.143,7849$ & 705.608 & 20.628 & 4.102 & 6.960 & 4,69 \\
\hline 1990 & 34.875 & 20.228 .122 & $2.751,1560$ & 735.259 & 21.083 & 4.192 & 7.113 & 4,79 \\
\hline 1991 & 35.546 & 26.106 .698 & $3.481,0045$ & 749.976 & 21.099 & 4.195 & 7.119 & 4,80 \\
\hline 1992 & 36.222 & 33.515 .046 & $4.295,0827$ & 780.312 & 21.542 & 4.284 & 7.268 & 4,90 \\
\hline 1993 & 36.900 & 43.898 .166 & $5.338,2339$ & 822.335 & 22.286 & 4.431 & 7.519 & 5,06 \\
\hline
\end{tabular}




\begin{tabular}{lcccccccc}
\hline Años & $\begin{array}{c}\text { Población } \\
\text { (Miles) }\end{array}$ & $\begin{array}{c}\text { PIB } \\
\text { (Pesos } \\
\text { corrientes) }\end{array}$ & $\begin{array}{c}\text { Deflactor } \\
\text { (Base: } 1975)\end{array}$ & $\begin{array}{c}\text { PIB } \\
\text { (Millones, } \\
\text { pesos de } \\
1975)\end{array}$ & $\begin{array}{c}\text { PIB per } \\
\text { cápita } \\
\text { (Pesos de } \\
1975)\end{array}$ & $\begin{array}{c}\text { PIB per } \\
\text { cápita } \\
\text { (Dólares } \\
\text { de 1990) }\end{array}$ & $\begin{array}{c}\text { PIB per } \\
\text { cápita } \\
\text { (Dólares } \\
\text { de 2011) }\end{array}$ & Índice \\
\hline 1994 & 37.579 & 67.532 .862 & $7.761,0509$ & 870.151 & 23.155 & 4.604 & 7.812 & 5,26 \\
1995 & 38.259 & 84.439 .109 & $9.224,0833$ & 915.420 & 23.927 & 4.758 & 8.073 & 5,44 \\
1996 & 38.940 & 100.711 .389 & $10.780,0366$ & 934.240 & 23.992 & 4.771 & 8.095 & 5,45 \\
1997 & 39.626 & 121.707 .501 & $12.595,3789$ & 966.287 & 24.385 & 4.849 & 8.227 & 5,54 \\
1998 & 40.311 & 140.483 .322 & $14.456,0999$ & 971.793 & 24.107 & 4.794 & 8.134 & 5,48 \\
1999 & 40.990 & 151.565 .005 & $16.280,8849$ & 930.938 & 22.711 & 4.516 & 7.663 & 5,16 \\
2000 & 41.661 & 196.373 .851 & $20.494,7410$ & 958.167 & 22.999 & 4.573 & 7.760 & 5,23 \\
2001 & 42.325 & 213.582 .653 & $21.814,9318$ & 979.066 & 23.132 & 4.600 & 7.805 & 5,26 \\
2002 & 42.985 & 232.933 .484 & $23.220,3982$ & 1.003 .142 & 23.337 & 4.640 & 7.874 & 5,30 \\
2003 & 43.637 & 263.887 .767 & $25.146,3222$ & 1.049 .409 & 24.049 & 4.782 & 8.114 & 5,47 \\
2004 & 44.279 & 299.066 .590 & $27.228,6944$ & 1.098 .351 & 24.805 & 4.932 & 8.369 & 5,64 \\
2005 & 44.907 & 340.160 .000 & $29.294,1583$ & 1.161 .187 & 25.858 & 5.142 & 8.724 & 5,88 \\
2006 & 45.518 & 383.892 .000 & $30.985,4383$ & 1.238 .943 & 27.219 & 5.412 & 9.183 & 6,19 \\
2007 & 46.116 & 431.072 .000 & $32.547,5379$ & 1.324 .438 & 28.720 & 5.711 & 9.690 & 6,53 \\
2008 & 46.702 & 480.087 .000 & $35.006,7321$ & 1.371 .413 & 29.365 & 5.839 & 9.908 & 6,67 \\
2009 & 47.301 & 504.647 .000 & $36.199,7289$ & 1.394 .063 & 29.472 & 5.860 & 9.944 & 6,70 \\
2010 & 47.899 & 544.924 .000 & $37.595,6842$ & 1.449 .432 & 30.260 & 6.017 & 10.210 & 6,88 \\
2011 & 48.497 & 619.894 .000 & $40.214,4103$ & 1.541 .472 & 31.785 & 6.320 & 10.724 & 7,22 \\
2012 & 49.095 & 664.240 .000 & $41.316,2030$ & 1.607 .699 & 32.747 & 6.511 & 11.049 & 7,44 \\
2013 & 49.694 & 710.497 .000 & $42.107,6106$ & 1.687 .336 & 33.955 & 6.752 & 11.456 & 7,72 \\
\hline
\end{tabular}

Fuente: sección sobre el método.

\section{Cuadro A2}

Composición del PIB, 1888-1929 (Porcentajes)

\begin{tabular}{|c|c|c|c|c|c|}
\hline Años & $\begin{array}{l}\text { PIB nominal } \\
\text { (Millones de } \\
\text { pesos) }\end{array}$ & $\begin{array}{c}\text { Consumo de los } \\
\text { hogares }\end{array}$ & $\begin{array}{l}\text { Gastos del } \\
\text { gobierno }\end{array}$ & $\begin{array}{l}\text { Exportaciones } \\
\text { Neto }\end{array}$ & Inversión \\
\hline 1888 & 179,11 & 87,03 & 3,73 & 0,57 & 8,67 \\
\hline 1889 & 179,65 & 87,84 & 3,74 & $-0,33$ & 8,75 \\
\hline 1890 & 160,82 & 89,22 & 4,20 & $-0,23$ & 6,80 \\
\hline 1891 & 153,36 & 87,91 & 4,43 & 0,25 & 7,41 \\
\hline 1892 & 166,09 & 89,10 & 4,12 & 0,89 & 5,89 \\
\hline 1893 & 171,72 & 88,23 & 4,01 & 0,68 & 7,08 \\
\hline 1894 & 154,64 & 86,14 & 4,48 & 3,31 & 6,08 \\
\hline 1895 & 146,29 & 88,07 & 4,77 & 1,86 & 5,30 \\
\hline 1896 & 148,73 & 87,78 & 4,72 & 1,12 & 6,37 \\
\hline 1897 & 178,63 & 93,75 & 3,95 & $-1,56$ & 3,85 \\
\hline 1898 & 159,97 & 84,66 & 4,44 & 5,06 & 5,84 \\
\hline 1899 & 152,89 & 87,44 & 4,64 & 1,77 & 6,15 \\
\hline 1900 & 156,67 & 89,61 & 5,31 & $-0,11$ & 5,19 \\
\hline 1901 & 152,83 & 92,97 & 5,51 & $-4,18$ & 5,70 \\
\hline 1902 & 153,32 & 91,74 & 5,56 & $-3,47$ & 6,18 \\
\hline 1903 & 168,25 & 89,92 & 5,11 & $-1,65$ & 6,62 \\
\hline 1904 & 178,98 & 87,55 & 4,86 & 0,42 & 7,18 \\
\hline 1905 & 174,20 & 87,49 & 5,04 & $-0,49$ & 7,97 \\
\hline 1906 & 170,11 & 83,33 & 5,92 & 2,35 & 8,40 \\
\hline 1907 & 172,26 & 81,33 & 9,00 & 1,39 & 8,28 \\
\hline 1908 & 177,45 & 82,73 & 7,89 & 0,84 & 8,54 \\
\hline 1909 & 233,83 & 81,97 & 7,25 & 2,02 & 8,76 \\
\hline 1910 & 229,79 & 85,61 & 5,08 & 0,17 & 9,13 \\
\hline 1911 & 217,54 & 85,17 & 4,53 & 0,96 & 9,34 \\
\hline 1912 & 255,49 & 83,66 & 4,76 & 2,11 & 9,48 \\
\hline 1913 & 287,32 & 84,29 & 5,30 & 0,82 & 9,58 \\
\hline 1914 & 329,35 & 82,18 & 5,30 & 2,77 & 9,74 \\
\hline 1915 & 368,20 & 81,23 & 3,94 & 3,15 & 11,68 \\
\hline 1916 & 366,86 & 81,49 & 5,93 & 0,76 & 11,82 \\
\hline 1917 & 403,15 & 81,14 & 4,31 & 2,24 & 12,32 \\
\hline 1918 & 503,99 & 79,87 & 4,85 & 2,59 & 12,69 \\
\hline 1919 & 556,90 & 77,94 & 3,85 & 4,65 & 13,57 \\
\hline
\end{tabular}




\begin{tabular}{lccccc}
\hline Años & $\begin{array}{c}\text { PIB nominal } \\
\text { (Millones de } \\
\text { pesos) }\end{array}$ & $\begin{array}{c}\text { Consumo de los } \\
\text { hogares }\end{array}$ & $\begin{array}{c}\text { Gastos del } \\
\text { gobierno }\end{array}$ & $\begin{array}{c}\text { Exportaciones } \\
\text { Neto }\end{array}$ & Inversión \\
\hline 1920 & 536,26 & 87,64 & 3,85 & $-5,66$ & 14,18 \\
1921 & 602,75 & 76,63 & 4,49 & 4,31 & 14,57 \\
1922 & 589,84 & 79,46 & 4,49 & 0,87 & 15,18 \\
1923 & 559,60 & 80,63 & 4,94 & $-1,24$ & 15,67 \\
1924 & 593,90 & 75,48 & 4,21 & 4,03 & 16,28 \\
1925 & 570,39 & 78,55 & 4,40 & $-2,17$ & 19,22 \\
1926 & 712,71 & 75,51 & 5,12 & $-1,72$ & 21,09 \\
1927 & 703,62 & 76,06 & 6,02 & $-4,29$ & 22,21 \\
1928 & 713,97 & 73,66 & 5,84 & $-4,03$ & 24,53 \\
1929 & 898,51 & 74,96 & 5,57 & $-1,63$ & 21,10 \\
\hline
\end{tabular}

Fuente: cálculos propios.

\section{REFERENCIAS BIBLIOGRÁFICAS}

Aguilera, R. (1994). Venezuela and Colombia: Border security. Tesis de maestría en Artes, Naval Postgraduate School. Monterrey, California.

AVN.(2010). Uribe convirtió a Colombia en base yanqui mientras Venezuela promueve la integración, [http://www.avn.info.ve/contenido/ uribe-convirti\%C3\%B3-colombia-base-yanqui-mientras-venezuelapromueve-integraci\%C3\%B3n].

Banco de la República. (1997). Principales indicadores económicos 19231997. Bogotá.

Díaz-B., S. y Frederick, M. J. (1984). Colombian emigration: A research note on its probable quantitative extent. International Migration Review, 18(1), 99-110.

Caro, M. A. (1993). Obra selecta. Caracas: Biblioteca Ayacucho.

Cepal. (1957). Análisis y proyecciones del desarrollo económico. El desarrollo económico de Colombia, anexo estadístico. México DF: Cepal.

GIR. (2018). Colombia's fracking dilemma. Oil prices. Global Intelligence Report.

DCL. (1907). Export of manufactures from de United States and their distributions by articles and countries. 1800 to 1906. Washington: Department of Commerce.

DNP. (1999). Estadisticas históricas de Colombia, [https://www.dnp.gov. co/estudios-y-publicaciones/estudios-economicos/Paginas/estadisticashistoricas-de-colombia.aspx].

Graham, H. (1912). Coffee production, trade, and consumption by countries. Washington: US Department of Agriculture.

Greco-Banrep. (1999). El desempeño macroeconómico colombiano. Series estadisticas 1905-1997, [ http://www.banrep.gov.co/docum/ftp/ borra095.pdf].

Greco-Banrep. (2004) El crecimiento económico colombiano en el siglo XX. Bogotá: Banco de la República y Fondo de Cultura Económica.

Guarnizo, L. E. (2006). E1 Estado y la migración global colombiana. Migración y Desarrollo, 6, 79-101.

INE. Estadísticas vitales. De 1874 a 2003, impreso; 1988-2010, digital. Censos 1961, 1971, 1981, 1990, 2001 y 2011.

Junguito, R. y Rincón, H. (2004). La política fiscal en el siglo XX en Colombia. Banco de la República. Borrador número 318. 
Kalmanovitz S. (1999). La producción agropecuaria colombiana 1915-1950. IDEAS RePec, [http://www.banrep.gov.co/docum/ftp/borra116.pdf].

Kalmanovitz, S. (ed.). (2010). Nueva historia económica de Colombia. Bogotá: Taurus- Universidad Jorge Tadeo Lozano.

Kalmanovitz, S. y López, E. (2009). Las cuentas nacionales de Colombia en el siglo XIX. Bogotá: Universidad Jorge Tadeo Lozano.

Kalmanovitz, S. y López, E. (2012). La agriultura colombiana en el siglo XX. Bogotá: Fondo de Cultura Económica y Banco de la República.

Lares, M. V. (2005). 12.379 colombianos, nuevos venezolanos. El Tiempo, 15 de julio. [http://www.eltiempo.com/archivo/documento/MAM1959006].

Lebret, L. J. (1958). Estudio sobre las condiciones del desarrollo de Colombia. Bogotá: D.E. Aedita, Editores Ltda. Cromos. Vol. 1 y vol. 2.

Lo Cascio, E. y Malanima, P. (2009). GDP in pre-modern agrarian economies (1-1820 AD). A revision of the estimates. Rivista di storia economica, 25,(3), 391-420.

López, G. 2015. Hispanics of Colombian origin in the United States, 2013. Washington, D.C.: Pew Research Center.

López U., M. P. (2011). Salarios, vida cotidiana y condiciones de vida en Bogotá durante la primera mitad del siglo XX. Bogotá: Universidad de los Andes.

Maddison, A. (2010). Historical statistics, [http://www.ggdc.net/maddison/oriindex.htm].

Medina, I. E. (2004). Chávez abre nacionalizaciones. El Tiempo, 9 de febrero, [http://www.eltiempo.com/archivo/documento/MAM-1512459].

Malanima, P. (2009). Pre-modern European economy. One thousand years (10th-19th Centuries). Leiden, Boston: Brill.

Meisel R., A. Ramírez, M. T. (eds). (2010). Economía colombiana del siglo $X I X$. Bogotá: Fondo de Cultura Económica y Banco de la República.

Meisel R., A. y Romero, J. E. (2017). La mortalidad de la Guerra de los Mil Días, 1899-1902. Cuadernos de Historia Económica y Empresarial, 43.

Montenegro, S. (2002). El arduo tránsito hacia la modernidad: bistoria de la industria textil colombiana durante la primera mitad del siglo XX. Medellín: Universidad de Antioquia.

Moxlad Base de datos Oxford América Latina, [http://moxlad-staging. herokuapp.com/home/es].

Ocampo, J. A. (1984). Colombia y la economía mundial 1830-1910. Bogotá: Siglo XXI.

Pardo P., A. (1972). Geografía económica y humana de Colombia. Bogotá: Tercer Mundo.

Pellegrino, A. (1985). Los indocumentados en la inmigración colombiana en Venezuela. Documento de trabajo 20, Caracas: Cim-Cimal.

Poveda R., G. (2005). Historia económica de Colombia en el siglo XX. Bogotá: Universidad Pontificia Bolivariana.

Poveda R., G. (2013). Población y censos en Colombia desde la Conquista hasta el siglo XXI. Medellín: Ediciones Unaula.

Queffelec, J. (2010). La migración aumentó con la gestión de Álvaro Uribe. Cada día huyen a Venezuela 300 colombianos y colombianas. Correo 
del Orinoco, 1 de agosto, [http://www.correodelorinoco.gob.ve/tema$\mathrm{dia} / \mathrm{cada}$-dia-huyen-a-venezuela-300-colombianos-y-colombianas/].

Sassen, S. (1979). Economic growth and immigration in Venezuela. International Migration Review, 13(3), 455-474.

Saavedra, N. (2012). Forja de una identidad nacional amalgamada: el europeo y el colombiano. En La literatura venezolana contemporánea. Tesis de doctorado, Florida State University.

Scheidel, W. (2009). Real wages in early economies: Evidence for living standards from $1800 \mathrm{BCE}$ to $1300 \mathrm{CE}$. Princeton/Stanford working papers in Classics, [https://papers.ssrn.com/sol3/papers. cfm?abstract_id $=1114424$ ].

Schwarz, T. (2016). 'I won't naturalize foreigners like crazy' The naturalization campaign in Venezuela, 2004-2006. European Review of Latin American and Caribbean Studies 101: 33-54.

Sistema de Información de Petróleo y Gas Colombiano, [http://www. sipg.gov.co/].

Tovar Z., B. (1984). La intervención económica del Estado colombiano 19141936. Bogotá: Biblioteca Banco Popular.

Urrutia, M. (2007). Precios y salarios urbanos en el siglo XIX. Documentos CEDE, [https://economia.uniandes.edu.co/components/com_booklibrary/ebooks/documentocede2007-25.pdf].

Urrutia, M. y Arrubla, M. (1970). Compendio de estadisticas históricas de Colombia. Bogotá: Universidad Nacional de Colombia.

Yáñez, C., Rivero, R. et al. (2012). La población de los países latinoamericanos desde el siglo XIX hasta el 2008. Ensayo de historia cuantitativa. Documento de trabajo 1202, Asociación Española de Historia Económica. 